Portland State University

PDXScholar

Fall 11-30-2012

\title{
Transgressing Sexuality: An Interdisciplinary Study of Economic History, Anthropology, and Queer Theory
}

Jason Gary Damron

Portland State University

Follow this and additional works at: https://pdxscholar.library.pdx.edu/open_access_etds

Part of the Feminist, Gender, and Sexuality Studies Commons, and the Social and Cultural Anthropology Commons

Let us know how access to this document benefits you.

\section{Recommended Citation}

Damron, Jason Gary, "Transgressing Sexuality: An Interdisciplinary Study of Economic History, Anthropology, and Queer Theory" (2012). Dissertations and Theses. Paper 622.

https://doi.org/10.15760/etd.622

This Thesis is brought to you for free and open access. It has been accepted for inclusion in Dissertations and Theses by an authorized administrator of PDXScholar. Please contact us if we can make this document more accessible: pdxscholar@pdx.edu. 
Transgressing Sexuality: An Interdisciplinary Study of

Economic History, Anthropology, and Queer Theory

by

Jason Gary Damron

A thesis submitted in partial fulfillment of the requirements for the degree of

\author{
Master of Arts \\ in \\ Interdisciplinary Studies
}

Thesis Committee:

Michele R. Gamburd, Chair

Mary C. King

Leerom Medovoi

DeLys Ostlund

Portland State University

2012 
C2012 Jason Gary Damron 


\begin{abstract}
This interdisciplinary thesis examines the concept of sexuality through lenses provided by economic history, anthropology, and queer theory. A close reading reveals historical parallels from the late 1800s between concepts of a desiring, utility-maximizing economic subject on the one hand, and a desiring, carnally decisive sexological subject on the other. Social constructionists have persuasively argued that social and economic elites deploy the discourse of sexuality as a technique of discipline and social control in class- and gender-based struggles. Although prior scholarship discusses how contemporary ideas of sexuality reflect this origin, many anthropologists and queer theorists continue to use "sexuality" uncritically when crafting local, material accounts of sex, pleasure, affection, intimacy, and human agency. In this thesis, I show that other economic, political, and intellectual pathways emerge when sexuality is deliberately disordered. I argued that contemporary research aspires to formulate new ideas about bodies and pleasures. It fails to do so adequately when relying on sexuality as a master narrative.
\end{abstract}




\section{Dedication}

This thesis is dedicated to Kevin J. Klein, my friend and domestic partner-in-crime. 


\section{Acknowledgments}

An education is an intricate collaboration among scholars, professors, peers, and friends. I offer my sincerest gratitude to all those who helped me, and encouraged me, and struggled with me along this path. I sincerely hope I was able to offer you equal support, or a few insights, or at least a few good laughs.

First, to my dear mentor, Professor, and advisor Michele R. Gamburd: Twelve years is a tremendous amount of time to remain so patient and enthusiastic about my work! I thank you with all the enthusiasm I can muster at the end of this winding, and occasionally bumpy, road. You never fail to inspire and challenge me. I remain committed to honoring all your investments in my studies. Thank you!

I would also like offer my wholehearted gratitude to: Candyce Reynolds (for always embracing my many ideas and efforts); Ann Mussey (for creating an opportunity for me to mentor and teach...you changed my life, Ann); Virginia Butler (a great teacher and mentor and scholar...I always think fondly of teaching our Archaeology class); Cherry Muhanji (you taught me how strong and loving a teacher can be); Connie Cash (for all the laughs, and all the help); Marcia Klotz (you are a great teacher and thinker...there was no queer theory until you taught me queer theory); Jonathan Walker (you always have the right touch in all your teachings); Professor Hall (thank you for helping my critical studies of Economics when I felt at a loss); thank you Mary King and Delys Ostlund for serving on my committee (and especially for your patience and candor); Leerom Medovoi (my sincerest gratitude for my assistantship and, of course, thank you for serving on my committee); Linda Hummer (I miss you and your radically joyful teaching); Wendy Morgaine (you picked me up at the lowest point of my early graduate studies); Robert Mercer (you are an amazing educator and compassionate man, and you saved my education...thank you); Margaret Everett (I am so appreciative of the helping hand you extended to me); Vicki Reitenauer (there are not enough words to express the joy I always feel in your company; I modeled much of my teaching on yours... and I owe you royalties!).

To my friends and family: Henry George, Elizabeth Jackson, Erin McGovney, Megan McGeorge, David Berger (ECS! and so many hours of collaboration), Shelagh Johnson, Andrea Gorman, Kara Carmosino, Jesse Grant, Brent Lank, Denise McNichols, Jamie Villa (one mile at a time sister...thank you for everything), Amberly Damron (for all the good times sis), and last, but not least, to my best friend Rinda Joy Chambers (thank you darling). 
Table of Contents



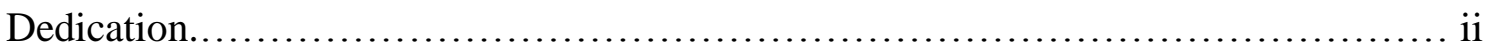

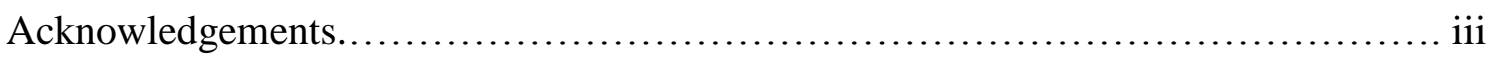

Chapter 1: Introduction and Deployments of Sexuality........................... 1

Introduction.........................................................

Setting the Terms and Methods.......................................... 9

Addressing Foucault: A Definition of Sexuality and Deployment......... 9

Critical Discourse Analysis and Sexuality........................ 14

Theories of Subjectivity and Materialist Feminism................. 17

Why an Interdisciplinary Study of Sexuality and Social Construction?............. 20

A Note on the Politics of Sexuality and Reflexivity...................... 27

Chapter 2: Neoclassical Economic Philosophy and the Subject of Sexuality............ 32



Parallel Criticism: Critical Discourse Analysis and Economic Literature........ 34

Classical Economic Subjectivity: Male, Rational, and Self-Interested.......... 37

Troubling Bodies: Neoclassical Economic Philosophy...................... 45

Troubling Bodies: Neoclassical Economic Philosophy and Sexology........... 49



Introduction.................................................... 64

Anthropological Queerness......................................... 68

Thinking Queer Anthropologically...................................... 77

Sex, Sexuality, and Economic Development Programs....................... 82

Queer Anthropology, Without Sexuality.............................. 90

Chapter 4: Conclusion................................................. 109

References............................................................. 111 


\section{Chapter 1: Introduction and Deployments of Sexuality}

\section{Introduction}

In this late-capitalist and neoliberal time, notions of a discrete sexuality circulate widely. The concept of sexuality forms a touchstone for sexual rights and narratives of sexual liberation. Sexuality is understood as the biological foundation for gay, straight, and other sexual orientations. Sexuality is conceived as a state from which springs sexual identities and sexual pleasures. Sexuality is assumed to be a naturally occurring psychological, biological, and entirely "real" human condition. Sexuality is then tapped to substantiate theories of deviance and morality and to justify therapeutic treatments, punishments, and separate "but equal" classes in contemporary society. Most sexualized narrations of contemporary human experience rely on the concept of sexuality and this, in turn, shapes contentious political issues about sex, affection, intimacy, and citizenship. In academic discourse, sexuality is used to make sense of diverse sets of cultural and social phenomena. It is necessary to ask, however, what is sexuality?

In this thesis I will examine how sexuality should not be understood as a bodily and psychological reality, as it generally is, but should be understood instead as an economic philosophy about the body. I follow the historical critique of Michel Foucault (1978) to establish my critical and historical stance on sexuality. In this thesis I aim to contribute to a critical study of sexuality by more fully elaborating how economic philosophies parallel sexologists conceptual development of sexuality. In other words, I understand sexuality as a social system that addresses the body and its pleasures, but in ways that seek to discipline and order bodies. The concept of sexuality orders and 
categorizes bodies through a system of self-scrutiny and self-discipline, and always against an ideal sexuality constructed as gendered and classed.

Some will argue that sexuality was developed to pertain to all bodies, everywhere. Certainly the aim of sexologists (the so-called practitioners of "sexual science" developing at the end of $19^{\text {th }}$ century) was to address all bodies. They did so by constructing sexuality with normative ideals that, I argue, paralleled and supported economic thinking about bodies, desires, and pleasures. Classical economic philosophers composed a central character and subject in their work: a noble, rational, gendered male patriarch. This ideal later merges with neoclassical economic philosophers' interest in thinking about consumption, desire, and individualism. Sexologists construct their model of sexuality with these normative standards and measures. This is the foundation of sexuality, and against which all "other" sexualities are then compared as evidence of deviance and perversion. In this thesis I closely ascertain how sexologists relied on economic thinking, worked from these economic ideals, and instilled economic philosophies in their construction of gendered and classed concept of sexuality.

My thesis on sexuality can reveal the implicit economic assumptions we engage, albeit unwittingly, when we use the concept of sexuality in our time. Namely, sexuality is a class-based and gendered ideal about the proper uses of the body, and sexuality addresses the body and pleasure in ways that parallel neoclassical economic ideals of proper consumption, proper desire, and proper rational individualism. I argue that employing sexuality as an analytical category severely limits other critical and material ways to understand bodies, pleasure, affections, and intimacy. Particularly, I will argue 
that employing sexuality in cultural studies limits queer theorizing, other political economic perspectives, and feminist criticism about the body and its pleasures.

After establishing sexuality as an economic philosophy of the body, I turn to examine queer theory and cultural anthropologists' assessment of sexuality. Queer theorists, and anthropologists employing queer theory, offer skeptical and critical studies of sex, gender, and sexuality. In general, they are critical of sex and gender studies that posit rigid trans-historical and cross-cultural equivalencies to sex, gender, and sexuality. In other words, queer anthropological theorists claim that sex, gender, and sexuality do not offer the same meaning in all times and all places. This is also the central stance for social constructionists: it is a historical fallacy to offer universalized and naturalized social concepts.

Social categories, social practices, and social understanding do not mean the same things, in the same ways, to all people throughout time. Social ideas, like sexuality, should instead be understood as constructed in particular times and places. This perspective allows me to ask, again: What is sexuality? How has it been fabricated as an idea and ideal? I hope to contribute a more nuanced assessment of a historically and socially constructed sexuality as, foremost, an economic philosophy of the body. I believe this perspective is underdeveloped in social constructionist theories of sex and in queer anthropology. I find it necessary to fill in this gap, and I hope my effort contributes to vibrant queer anthropological studies.

I offer both support and criticism of queer anthropological efforts in this thesis. I support the necessity for these studies, and the valuable contributions queer anthropology can offer to cultural studies of bodies and pleasures. I note how queer anthropologists are 
satisfyingly skeptical of universalized notions of sex, gender, and sexual identity. Yet, I ask why this critical stance does not more thoroughly engage criticism of sexuality as an ideal analytical category. I criticize these studies for not taking social constructionist criticism more seriously. I accept Foucault's charge as fundamental and urgent: "The rallying point for the counter-attack against the deployment of sexuality ought not to be sex-desire, but bodies and pleasures" (1978:158).

I extend this "counter-attack" on sexuality by further developing the idea of sexuality as a regime of class and gender-based control and order, and in doing so I hope this helps develop new research strategies in queer cultural and anthropological studies. I am particularly concerned with this because queer theorists and queer anthropologists contend their research is necessary for a nuanced, political, and material understanding of bodily pleasures and affections. We should fully interrogate sexuality for embedded economic assumptions. Through illustrating the roots of sexuality in economic philosophy, I hope my study contributes to a more critical stance on the use of sexuality as an analytic category in cultural research.

I rely on the distinction that Rogers Brubaker and Frederick Cooper (2000) demarcate. They exhort social and cultural scholars to pay close attention to the distinctions between "categories of practice" and "categories of analysis." Social actors and social organizations use categories of practice to make sense of everyday situations and create cohesive meaning and understanding in social relations. This does not necessitate use of the same categories for social analysis (2000:5-6). Brubaker and Cooper demonstrate this point in a critical discussion of "identity," and use "race" and "nation" as additional examples of categories used as people's daily and lived categories 
of practice (2000:6-8). This practical use does not necessitate the category always be used in analysis, however. For example, people will employ the category of the nation in a vast array of social institutions and social practices. This use does not make the nation more of a material, analytic reality even when humans rely on it as a fundamental category to organize and understand meaning. The nation is as much an "imagined community" as it is a place of borders and internal and external locations (Anderson 2006). I attempt to offer a similar critique of the category of sexuality.

In the remainder of this introduction I will preview the remaining chapters, then further detail Michel Foucault's definition of sexuality and the concept of "deployment." I use Foucault's definition to begin and ground my study, but I further elaborate on the embedded economic philosophies. I believe this is a necessary elaboration on his criticism, and one that has not been adequately accomplished. I then closely set my interdisciplinary methods and theories: critical discourse analysis, theories of subjectivity, and materialist and feminist-based criticism. This is necessary because an interdisciplinary study, by design, has no proper disciplinary home. Though frustrating at times, engaging various disciplinary perspectives and methods can be fruitful, and may lead to new ways of addressing bodies, pleasures, affections, and intimacies.

I will follow these disciplinary notes with a brief reflection on the politics of sex and sexual justice. In doing so, I respect a tradition of reflective thinking in contemporary queer anthropology and queer theory. This tradition values the writer's reflections on social position and influences; this allows me to reflect on why I think this study is necessary and important beyond theoretical and institutional rubrics. This helps me contemplate what I hope this thesis offers to the reader, political economist, and queer 
anthropologist. It also allows me to share with my reader reflections on who inspired this study and reflect further on what this study may offer to those I care for and about.

In Chapter 2, I compare neoclassical economic philosophies to the sexological development of sexuality. Sexology is sexual science development in late $19^{\text {th }}$ and early $20^{\text {th }}$ century. Sexological theory and practice continues today. I explain how sexuality is implemented to rationalize pleasures and affections into the prevailing economic order, and is used to explain and then limit perceived threats to this order. Sexologists transformed discordant ideas about sex into an emerging theory of sexuality. Neoclassical economists make economic action and human behavior intelligible in ways that ultimately benefit the interests and concerns of a ruling class. The neoclassical conception of human behavior is gendered and classed; upper-class men are the foundation for neoclassical economic philosophy. Sexologists distill similar perspectives on bodies, pleasures, and affections; sexuality is imagined to account for all manifestations of pleasurable and affectionate behavior, no matter where humans reside.

Any deviation from the classed and gendered norm is troubling to sexologists and they attempted to explain behavior in remarkably similar ways to neoclassical economists. I emphasize how sexuality developed as an efficient register of social interpretation, discipline, and control. In other words, sexuality is developed to interpret behavior of bodies within a particular framework that emphasized the necessity of order and control of diverse bodily pleasures. Sexuality is normalized with a Western, capitalistic ideal of a nuclear family, and with normative desire fixed to an imagined masculine, rational, consumer psyche. This philosophical synergy is especially evident in sexologists' attempts to form an overarching theory for sexual desire and sexual cultural 
diversity for the entirety of humanity. This discourse also tightly frames sexuality to an assumed "natural order." Accounts of human sexual behavior must circulate then, and now, through this economic philosophy of the body. Earlier in political economic history, Adam Smith (1909[1776]) famously proposed an invisible hand guiding labor and a market economy. Sexologists propose a similar apparition guiding bodies, pleasures, and affections - and they name it sexuality. I argue that this orientation mystifies the economic epistemology at the core of sexuality. This mystification is very troubling when sexuality studies are often assumed to shed light on political economic class conditions, and somehow counterbalance economic misery through the liberation of bodily pleasures.

Throughout the $20^{\text {th }}$ century, sexual progressives and sexual liberationists argue that sexuality contained the repressed potential to overthrow economic miseries. Capitalism was imagined to repress sexuality (Marcuse 1966; Reich 1963) instead of producing it. Justifications for economic inequity often appeal to ideas of an already classed, immutable order, and sexuality follows with similar assumptions. Although sexuality is at times contested in $20^{\text {th }}$ and $21^{\text {st }}$ century social and cultural research, core gendered and classed economic assumptions remain. This continues to benefit a society and economy beset with unequal class relations and class discriminations - despite the supposed universal whispers of sexual freedom. Understanding sexuality as an economic philosophy is crucial for critical re-assessment of queer anthropology and cultural research.

In Chapter 3, I examine how anthropologists and queer theorists contest sexuality as a universal frame for understanding pleasure, affection, intimacy, and social agency. I emphasize how certain anthropological and queer thinkers navigate the social 
construction of sexuality while paying attention to the context of lived, material experiences. In other words, I demonstrate the dilemma of theorizing with social and cultural constructionist ideas while simultaneously attempting to account for social agency and social resistance. I assess the difficulty and rewards when applying social constructionist theories to the practices of everyday life. This approach sustains a creative tension for thinking about sexuality. I name this tension a "queer dilemma."

I conclude Chapter 3 by detailing queer anthropological efforts. Despite brilliant contestations of sexuality in this combined field of knowledge, queer anthropologists maintain sexuality in problematic ways. This constrains anthropological and queer holistic visions of sex and affection as materially expressive of social agency and culturally and locally specific. I advocate for a more thorough deconstruction of sexuality - a critical analysis that can emphasize the material limits of sexuality as an analytical category of research. I gauge other concepts that may be more imaginative for research: theories of carnality, pleasures and affections, queer sensations, and valuing descriptions of tacit understandings and knowledge. Sexuality, on the other hand, limits the development and use of imaginative research questions even when we profess awareness of the historical construction of sexuality.

Queer anthropology needs to do more than gloss the historical and social construction of sexuality. It is not enough to point to contested definitions of sexuality, and then proceed as if this realization does not affect the ordering and maintenance of knowledge about bodies, pleasures, affections, and agency, in the first place (Oleksy 2009; Altman 2001; Binnie 2004; Leap \& Lewin 2002). This is even more confounding when much of the work I discuss both creatively and lovingly builds alternate theories for 
understanding pleasure and agency in lived ways (Povinelli 2006; Decena 2011;

Valentine 2007). Queer anthropology is capable of addressing these dilemmas with thorough attention to the use and misuse of sexuality as a category of analysis.

\section{Setting the Terms and Methods}

\section{Addressing Foucault: A Definition of Sexuality and Deployment}

Michel Foucault (1978) exposes the deployment of sexuality as a modern technique of social organization. He argues that sexuality was "deployed" to accentuate how sexuality was not "discovered" in the naturalistic sense, but instead emerges from the cross-fertilization of overlapping social discourses concerned with bodies and pleasures. These include discourses of the religious confessional, the ideal of repressed sexual knowledge (which he refutes), and the establishment of professions and government practices that made sex their object and subject of scrutiny. Foucault argues that sexuality was named and deployed to categorize, order, and discipline bodies. His effort notes that institutions manage and, in effect, dominate bodies. This management and domination works through material practices, but it also works through a production of subjectivities derived from categorical inventions. Through this deployment some sexual acts are named as perversions of natural orders, and social members are tagged with these sexual notations. He named this process a "perverse implantation" because it categorized certain sexual acts and behaviors as reflective of person's "real" self (Foucault 1978:36-40). He contends this process initiates our contemporary conception of sexuality as the psychologically deepest and most truthful part of the individualized self. 
In other words, invoking sexuality encourages the belief that sexuality is a preordained and indispensable aspect of being human.

Foucault was intensely concerned that an unwavering belief in this naturalness of sexuality ignores the social and historical processes creating it as a category, in the first place. It also ignores the constellations of power and knowledge that operate through it. Foucault encourages his readers to assess sexuality as a social technique of control that encourages self-discipline and self-scrutiny. This assessment contrasts with psychological, biological, and other Western, conventional models of human sexuality. It also contradicts explanations of sexual orientation as physiologically pre-determined. The human body contains no "natural" sexuality, according to Foucault.

I follow Foucault's lead to understand the human body as inscribed with the discourse of sexuality and fashioned with its particular assumptions: what is erotically possible, what is supposedly natural, and what is essential to the human understanding of the self? This estimation of sexuality upends the established psychological tradition that composes sexuality as an internal, cognitive development built from of the gravels of sexual repression and following a predetermined and necessary path. It is important to note that this is not an estimation of sexuality that competes with other accounts of sexuality — it is the very basis for sexuality in the first instance. For this study then sexuality is a "name that can be given to a historical construct... a great surface network in which the stimulation of bodies, the intensification of pleasures, the incitement to discourse, the formation of special knowledges, the strengthening of controls and resistances, are linked to one another, in accordance with a few major strategies of knowledge and power" (Foucault 1978:105-106). In this way, Foucault notes how the 
deployment of sexuality built over alliances of kinship that governed the cultural regulation of bodies prior to an invention of sexuality (1978:103-114). But the deployment of sexuality did not supplant cultural formations of kinship, instead it mapped over structures of kinship with a new ideal of "sex" as a category and in service of sexuality (1978:107). According to Foucault, sexuality is thus deployed along four major "privileged objects of knowledge" (1978:104-106). In other words, four social anxieties roused the establishment of sexuality: the "hysterical woman," the selfpleasuring child, the fertile couple, and the perverse adult (1978:105).

Foucault was aware, as am I, that many will question why it is necessary to separate off sexuality from sex (1978:150-153). In other words, can sexuality be cleanly understood as an analytic category that simply organizes our appraisals of sex? Why all the fuss? Foucault emphatically dismisses this idea. He notes that sex should not be simply understood as some prior and universal human register of bodily experience. Sex is made socially intelligible, named, and ordered through the deployment of sexuality (1978:150-157). Sexuality is not a simple commentary on the capacity of human bodies to experience sex, and thus sex is not an inherent natural component of sexuality. Both concepts are historically and socially invented to interpret, manage, order, and discipline human bodies in particular ways. Surely, the body is biologically capable of pleasure, reproduction, affection, and emotional intimacy, but these are not dependent on sex and sexuality. The concepts of sex and sexuality are the tools of a regime of power/knowledge that made these notions intelligible in our time, and for specific purposes that I argue are worthy of more critical interrogation. The paradigm of sexuality needs further interrogation because of the limits it places on our ability to understand 
pleasure, affection, and intimacy, not because it will forever help us further refine sexuality as a category of analysis.

I hope my criticism of sexuality foregrounds how it is constructed to catalogue and stigmatize human bodies and pleasures, but I also hope it demonstrates how the invention of sexuality channeled concerns about changing social relations, and thus reflected anxieties about rapidly transforming material conditions. In this sense, knowledge of sex and bodies "was not discovered so much as deployed, made to sustain new relations of power (between men and women, physicians and patients, parents and children), which in turn enhanced the credibility of the knowledge" (Allen 1999:71). I am trying to show that theories of social construction clearly violate paradigmatic thought on the naturalness and essentialness of sexuality. This violation demands a reversal of thinking: "For all of us, essentialism was our first way of thinking about sexuality and still remains the hegemonic one" (Vance 1989:160). Despite the challenge of this reversal and given the intellectual influence of Foucault's ideas, I still remain surprised how positivist and empirical attempts to establish sexuality (or one should say homosexuality and "other" sexualities) demand attention and allegiance.

Foucault's monumental History of Sexuality, Volume 1 (1978) is valorized and consistently cited throughout the academic disciplines. But, it seems that his most crucial point is too comfortably forgotten: sexuality should be understood as a particular historical schema that organizes an understanding of pleasure and affection through the management and control of material bodies and affective alliances. I will add to this conception by focusing on the classed and gendered way this disciplining and ordering works. Feminist critics argue that Foucault often missed this vital dimension in his study 
(Sawicki 1991; Hennessy 1993). I assess economic and sexological literature by focusing on class conflicts and class tensions within the development of this deeply gendered and economical sexuality. I hope to make this connection clear and show how sexuality was invented and refined as a commentary on the bodies of laboring classes, migrants, women, and non-normative affections and pleasures. Much good work addresses the way sexuality was invented to fit all bodies, and multiple thinkers assess the way sexuality was fabricated to address the pleasures and perils of bourgeois bodies. But I will emphasize the differential equation of class and gender in the invention and ordering of sexuality, and why this presents a profound dilemma for contemporary queer cultural research.

Even in the intellectual aftermath of Foucault's insights, the analytical ideal of sexuality remains unfortunately and firmly rooted in cultural research. Even when social and cultural research addresses Foucault's pointed criticism, sexuality still remains the intellectual container for making pleasure and affection recognizable, meaningful, and ahistorical. In this way, I fear that sexuality still serves to justify social and political hostility to migrants and laborers, sexual "deviants," gendered bodies not marked as masculine, and bodies that refuse to follow normative social rules. These valuable bodies are snared in class disputes that result in vigilante surveillance and piece-meal punishments. For example, perhaps this critical and interdisciplinary study of sexuality can help illuminate why some bodies are allowed to cross national and international borders for love, marriage rites, and affection, and others are not. It may clarify why contemporary age-of-consent laws punish people for affection that does not adhere to political standards of sexual maturity and proper citizenship. It may help provide further 
insight into why HIV/AIDS prevention organizations were compelled to adopt categories like MSM (men-who-have-sex-with-men) in practice, and mostly abandon categories of gay, lesbian, and bisexual. I hope to critique why, despite the elaborate human complexity of pleasures, affections, and accounts of human agency, sexuality remains the primary backdrop in social and cultural research for negotiating the intricacies of bodily meaning. It is not enough to gloss over a "constructed sexuality" and then ignore what insights this realizes. I ask: what other intellectual pathways may emerge when sexuality is dis-ordered in this critical and necessary way?

\section{Critical Discourse Analysis and Sexuality}

I aim to critique the economic deployment of sexuality through a lens of critical

discourse theory. Sara Mills (1997) discusses discourse in the following way:

Influenced largely by Foucault's work, within cultural theory as a whole, discourse is often used in an amalgam of the meanings derived from the term's Latin and French and influences (a speech/conversation) and a more specific theoretical meaning which sees discourse as the general domain of the production and circulation of rule-governed statements. A distinction may be usefully made between this general, abstract theoretical concern with discourse and the analysis of individual discourses, or groups of statements produced within power relations. [Mills 1997:9]

These power relations are understood as situated in the institutions that govern discourse and the relations of governance (Macdonnell 1986:3). As noted, questions and criticisms inspired by Foucault's work are common in contemporary intellectual thought. The critical methods he developed continue to warrant use here for several reasons. First, 
critical discourse theory recognizes that discourse changes over time but maintains genealogical relations to the past. Second, new perspectives on present conditions compel re-examination of past meanings and help one ask whether current social orders and material distributions adequately address current material realities. Third, critical discourse theory aids in imagining new ways to live, form politics, and demand change in the present.

Importantly, the status quo in politics, in economic models, and in cross-cultural research agendas can be confronted with critical discourse analysis. This method focuses concern on the way political power relations maintain existing social relations. Using this lens, I am able to assess how notions of sexuality govern what can be said, how it can be said, and what is rendered as the possibility of truth within those structures (Mills 1997:48-51). Michel Foucault makes clear that a dominant discourse does not totalize all possibilities of discourse, and a dominant discourse does not propose that a hunt for some absolute, powerful cause of terminology is useful:

Discourses are not once and for all subservient to power or raised up against it, any more than silences are. We must make allowances for the complex and unstable process whereby discourse can be both an instrument of and an effect of power, but also a hindrance, a stumbling block, a point of resistance and a starting point for an opposing strategy. Discourse transmits and produces power; it reinforces it, but also undermines it and exposes it, renders it fragile and makes it possible to thwart it. [Foucault 1978:100-101]

Demarcating sexuality as complex and saturated with obedience and resistance adequately meets Foucault's challenge to avoid assuming ideas have obvious, direct, material causes alone (McNay 1994:108). 
This approach also helps me explain how "the discursive and the material are linked together in the symbiotic relationship of the power-knowledge complex" (McNay 1994:108). Foucault traces formations of power and knowledge and their intrinsic linkages and mutual dependence: "It is to give oneself as the object of analysis power relations and not power itself" (Foucault 1994:339). So my use of discourse theory must account for power/knowledge as a productive force. All discourse is always interwoven with resistance. Productive power meets resistance and saturates the entire discursive structure, and all those subjects defined by their relation to it (Rabinow 1994: xiv-xvii). Foucault designates bio-power as the set of power relations expressed in the technologies of managing populations under the auspice of social interest (Foucault 1978:137-144). Bodies are then regulated, controlled, and dominated through ideals of public health, conceptions of public safety, and notions of social risk. Sexuality is exemplary of the idea of bio-power.

I propose that discourse analysis can turn our attention away from an ideal that we can and will "get to the bottom of sexuality," and instead offers new ways to think of human bodies in resistance to the coordinated deployments of sexuality. People rely on the stipulations of sexuality as a category of practice, but we can be more critical of sexuality as a necessary and always applicable category of analysis. I will demonstrate a critical discourse analysis on the economic pedigree of sexuality offers new ways of thinking and may prompt new questions about bodies, pleasure, and social agency. Through discourse analysis we can continue to "replace an Idealist philosophy of final emancipation with a nominalist philosophy of endless revolt" (Rajchman 1985:93). 
Sexuality is just one of many social regulatory regimes interested in bodily acts, but it remains a massively influential one worthy of a revolt against its analytical standards.

I hope this confrontational stance offered by critical discourse analysis endures herein. Contemporary regimes continually establish an opposite supposition that sexuality is an inherent and essential condition for pleasure and affection, and it also proposes sexuality as irrefutable material for a final emancipation from social, sexual control. I resist this interpretation and believe my work will help others resist this interpretation.

\section{Theories of Subjectivity and Materialist Feminism}

A theory of subjectivity in its most compact form asks, "What is the self?" Answering this question is complicated after postmodern and post-structural pronouncements of a "death of the subject" (Mansfield 2000:v). Human subjectivity also represents discursive constructions-humans are always in the making of themselves. In other words, humans are always in the process of becoming. Critical discourse analysis provides a method to theorize subjectivity, and it remains a necessary anthropological analytical tool "where an idea of the cultural remains of value for a mediating experience" (Mansfield 2000:vi). In this thesis I work from a theoretical conception of subjectivity to provide "the inclusion of an important dimension of the social into the analysis" (Wuthnow et al 1984:242). Subjectivity is an expedient way to discuss the interlacing of power and knowledge and to assess the place of the human sexual subject in any regime. This cultural reality "is necessarily rooted at some level in human subjectivity" (Wuthnow et al 1984:242). This provides me with a tool to ask what "human" is theorized by discourses concerned with bodies, pleasures, and affection. 
This tool also allows me to comment on the "dynamic and unsolved tension between the bodily, self, and social/political processes that, we hold, is the core of subjectivity" (Biehl et al 2007:15). I connect a theory of sexual subjectivity to the critical stance of materialist feminism. Theorizing discourse and subjectivity allows me to further assess the complications of lived, material realities. I then can rely on the materialist feminist criticism that these lived realities are inherently gendered and class-based. I find this contestation necessary to resist the regime of sexuality across disciplinary studies. In doing so I can ask, "What is the gendered and classed human sexual subjectivity—named sexuality?" Materialist feminist criticisms can conflict with theories of discourse and subjectivity, but at least materialist theories foreground lived realities of empirical human practice, labor, and life.

This interdisciplinary effort seems to demand a new language entirely. But a new language is, at times, all that will suffice. Mikhail Bakhtin (1981) offers a similar invocation of language. He argues that language can control the consciousness and thus imagined social possibilities. Language, for Bakhtin, is an idiolect of class and social stratification. The term "idiolect" describes how language functions as a class-based prison for the imagination, restricting options in social thought and intentionally narrowing all thought into a monoglossia (one form, one thought, and one language). Though societies are by default heteroglot (multiple varieties of language) the effort to hem this heterogeneity in is ongoing. Only contestations of language will free one's thinking and open the mind to new knowledge which "frees consciousness from the tyranny of language, and its own myth of language" (Bakhtin 1981:61). This profound assertion about language, discourse, and social possibility is also illuminated by the 
materialist feminist considerations of class and gender. Class constructs the idiolect and works to reduce social possibility and, literally, new thoughts.

I employ the concept of materialism from Donna Landry and Gerald MacLean in Materialist Feminisms (1993). A materialist analysis of culture is "informed by and responsive to the concerns of women, as well as people of color and other marginalized groups" (Landry and MacLean 1993:x). This standpoint and method offers a "critical investigation, or reading in the strong sense, of the artifacts of culture and social history, including literary and artistic texts, archival documents, and works of theory." In addition, I find materialist analysis can fit with discursive analysis and provide a similar "potential site of political contestation through critique, not through the constant reiteration of home-truths" (1993:xi). My use of class and class terminology like worker, laborer, and bourgeois I take from Marxist analysis. In addition "Marxist feminism holds class contradictions and class analysis to be central, and has tried various ways of working an analysis of gender oppression around this central contradiction...materialist feminism should recognize as material other contradictions as well... ideologies of race, sexuality, imperialism and colonialism and anthropocentrism, with their accompanying radical critiques" (Landry and MacLean 1993: 229). I engage my critical discourse analysis with this gendered and class critique.

I purposefully use the terms pleasure, affection, intimacy, and social agency to limit the use of desire, sex and sexuality, and choice. I find these latter terms weighed down with contradictory and damaging meanings and histories. Specifically, the term "desire" summons much of the economic and psychological discourse that I criticize in Chapter 2. Equally, I avoid the notion of "love" because it presents such an expansive 
opening of possible meaning. I leave it out entirely in favor of the terms affection, affective alliances, and intimacies. I take a cue from Charles Lindholm who argues against romantic love being a human universal (1998:243-263). The concept of choice, as well, parallels the ideals of economic consumption too closely to be useful for my argument. I employ "queer" throughout this thesis. I do not employ this term as a category of specified sexual identities, but as a critical stance that works to destabilize the possibility and necessity for stable "sexual" identities.

\section{Why an Interdisciplinary Study of Sexuality and Social Construction?}

A project on "sexuality" engages seemingly endless crossroads of meaning, application, and consequence. Primarily, sexuality in most academic disciplines is assumed to be universally, socially, culturally, physically already "there"- a ground on which to build knowledge, contest derivative meanings, and perhaps argue for alternative ways of being. In other words, making an inquiry into the social construction of sexuality is not an original question or criticism in social and cultural research. The reverberations from this knowledge and "what to do with it," though, remain contested in academic disciplines, research projects, and economic development projects.

I ask why the deep and rich contribution of social constructionist thinking on sexuality has not sufficiently destabilized the concept in social and cultural research. I certainly imagined it would when I "discovered" it as a student. Why, despite the tremendous influence of social constructionist theories, does sexuality remain the de facto interpretation of the body and its pleasures? Why do cultural and social theorists continue to deploy the category of sexuality while invoking social construction theory as a frame 
for research? It is far more comprehensible when the discourses of psychology, medicine, biology, sexology, and sociology invoke sexuality, since a supposedly natural sexuality is historically invented and cemented within these disciplines. But within other critical studies, why do thinkers simultaneously position research as social constructionist, yet ignore the blunt and limiting scope of sexuality as an explanatory structure? Even more confounding, why would some queer cultural research take a strident stand for social constructionist elucidation, but simultaneously offer sexuality as a meaningful heuristic and philosophy of the body? It is as if a scholar devoted to critical race studies decided that race was a biological reality, after all. Clearly, there is more intellectual work to be done and these concerns inspire this thesis.

As a student, I traversed the de-territorialization and dis-orientation of a bodily sexuality across academic disciplines. At first, I naively imagined a different world emerging from the heap of ashy essences that social construction blithely burned through. I now must account for the limits of this type of critical engagement, as well as what further engagement may still promise. Even in the most critical studies of sexuality, the ideal that sexuality offers a necessary summary of pleasure, affection, agency, and material life remains. This realization is a particularly disturbing problem among research aiming to counter hegemonic social forces and debasing economic and political conditions. Contemporary sexual research may aspire to formulate other ideas about sex, pleasure, materiality, and human agency, but often fails to do so. I offer a criticism of intellectual practices that deconstruct sexuality only to counterintuitively deploy it, yet again, as a human universal measure. I hope to demonstrate that other ways of thinking about pleasure, materiality, and human agency are intellectually possible when the blunt 
force of sexuality (and its limited capitalistic vision of bodies and pleasure) is eschewed. In other words, I want to argue that sexuality is a capitalist axis for normative ideals of gendered and class-based pleasure and embodiment.

I select economic history, cultural anthropology, and queer theory for this thesis study. I do so because of the following considerations. First, I examine sexuality in relation to economic philosophy because of my concern with material inequalities in society. Second, I selected cultural anthropology for closer study because it generally attempts a holistic study of material conditions and human subjectivity (Roseberry 2002; Patterson 2001:103-164; Kurtz 2001:14-15; Wolf 1982). Both economic philosophy and cultural anthropology have been criticized for avoiding the topic of "sex" in research (Weston 1993, 1998; Lyons \& Lyons 2004; Markowitz \& Ashkenazi 1999; Kulick \& Willson 1995). I note, instead, that close reading of economic and anthropological literature demonstrates a depth of theorizing concerned with sexed and gendered bodies. Economists and anthropologists do not necessarily avoid "sex," but too often assume its coherent presence as "sexuality." Finally, queer theorists explicitly devote their research to social constructionist theories of pleasure, affection, and social resistance, but queer theories are routinely criticized for evading materialist and economic reckoning (Hennessy 2000; Wolf 2009). Nevertheless, queer theories form a gratifyingly skeptical study of normative beliefs.

In each of these disciplines, contentious debates about materialism, social agency, and bodies and pleasures remain ongoing. I find these intersections rewarding and productive ground for my thesis. My attempt to materialize pleasure and social agency and destabilize the category of sexuality in queer anthropological work is complicated. It 
requires this holistic, interdisciplinary study. Although I explicitly acknowledge this interdisciplinary focus, I do perceive my study following an anthropological tradition, and I attempt to maintain an anthropological perspective throughout.

The anthropological perspective prompts me to remember people are flesh and blood, cultural animals governed by forces often outside our planning and control. This prepares me to pay close attention to the material realities that govern human life. John Gray asserts in Straw Dogs: Notes on Humans and Other Animals:

Today, for the mass of humanity, science and technology embody 'miracle, mystery, and authority'. Science promises that the most ancient human fantasies will at last be realized. Sickness and aging will be abolished; scarcity and poverty will be no more; the species will become immortal. Like Christianity in the past, the modern cult of science lives on the hope of miracles. But to think that science can transform the human lot is to believe in magic. [2007:120]

I find this quote especially helpful for guiding my critique of sexuality. Sexuality is imagined to be an essential understanding of all human life and bodies. John Gray's assertion helps me realize that human bodies and pleasures will always remain too dynamic for any totalizing explanation. I also think this insight is pivotal for maintaining an active anthropological imagination and an idea of holism within cultural study.

In undertaking this project, I endeavor to piece together the puzzle that persisted throughout my interdisciplinary studies. Again, why does sexuality endure despite the deep and profound criticisms launched at it? Can my criticism herein prompt some change in queer anthropologists' theories and criticism? How can we ask new questions about pleasure and affection that prompt changes in ways we might imagine political 
agency and social solidarity? Is it possible to re-cast sexual orientations and gender expressions as evidence of resistance to debasing modes of life in late-capitalist, neoliberal economies?

Lately, I am afraid that sexual and political theorists have been lulled into addressing diverse human affections and pleasures as simple distillations of capitalistic development and progress. Importantly, if sexuality is used as a category to orient sex, pleasure, affection and social practices, then what other possible interpretations are lost? Contemporary Western sociality demands allegiance to a tangible sexuality in identity politics, liberal philosophy, economic alliances, and registers of intimacy and citizenship. A study of political economy and sexual subjectivity in queer anthropological research can, and must, proceed without sexuality as the primal explanation for bodies, pleasures, and affections. I cull examples from my local community to demonstrate a queer anthropological perspective. I hope to appeal to the local reader, too, but I aim to demonstrate the need for critical attention to political economic and queer anthropology at home, as well as in other locations.

In metropolitan Portland, Oregon homeless shelters were increasingly full after the last economic recession. Gender segregated dormitories were the prevalent organizational structure among the majority of shelters. Couples, whether in new relations, married, or otherwise companioned, were disallowed from sleeping together, or even in proximity to each other (Saker 2009). The necessity for safety in dormitory settings was made clear, but the assumption remained that a need for shelter trumps (and supposedly should trump) any affectionate alliances among those who needed shelter. 
The dignity of affectionate relations was apparently dependent on the possession of property.

Next, the Mayor of Portland, Oregon, Sam Adams was implicated in a 2008 "sex scandal" where he was accused of an affectionate and sexual relation with a 17 year-old male. Local newspaper Just Out refused to support the Mayor, although previously playing a large role in organizing electoral support. Local media coverage of the ensuing scandal honed in one theme: how "hurtful" Adam's act was for the local, "gay" community (Lang 2009). No local media ("gay" included) considered that a sexual and affective culture with affiliations of older men of middle-class standing, and younger, working-class men migrating to the city is an important, long-recognized, and even celebrated part of the so-called sexual minority community (Boag 2003). In any case, a 17 year and 11-month old male high school graduate is not a world apart from an 18 year-old male high school graduate. No one would speak to this in the local media. Even putting aside the historical amnesia that girds this "sex scandal," the Mayor offered a typical US political apologia for a lapse in moral judgment that this altogether common, affectionate companionship supposedly revealed. Political fortitude, in this case, was determined by the demand for sexual piety among the heteronormative political class in this sexually "progressive" city.

Another example: US West coast institutions of elementary education reveal a certain sexual piety. Debates about curriculum and textbooks and the necessity, or not, of including gay and lesbian historical contributions remains a controversial and divisive topic (Christie 2006). Both sides take aim at an unnervingly similar goal: to fix the identities of citizens into the regimented framework of contemporary sexuality. Whether 
self-identifications and self-conceptions might offer a more valuable historical rubric of sex and social agency is lost in the drumbeat of contemporary politics; both sides demand retroactive historical readings for political gain in the present.

Finally, I would like to note a personal example: across the years of my own collegiate study I received student health insurance. Meanwhile, dear friends of mine suffered from ailments from the common (broken bones) to the catastrophic (life threatening auto-immune disease). In either case, adequately caring for my own affective kin was made impossible by the stringent guideline that families are made through blood kinship, marriage, and domestic partnership alone. The chance to form a "family" outside of the structures of marriage and dependency is severely limited or non-existent. In my case it would require marrying or partnering with more than one person (clearly illegal), or claiming my affective kin as economic dependents (more legal, but a bureaucratic minefield). As my close friend noted with humor, "Maybe you could adopt me?" The rules of kinship reduced access to material benefits of health care.

The shadow of sexuality looms in each of these examples. All are justified with particular economic, juridical, or social principles rooted in the supposed primacy of a presumably transparent and obvious rationale. They each depend, though, also on what Monique Wittig (1978) argued is the "straight mind." These examples expose an obliviousness and reductionism about pleasure, intimacy, and affection that Eve Kosofsky Sedgwick criticizes in the Epistemology of the Closet (1990). I hope these local "queer dilemmas" illuminate for the reader the contemporary practices that utilize allegiance to sexuality, and in doing so, limit other values, meanings, and possibilities for resistance. In other words, it is not only what "happens," but what is allowable to note, 
what is allowable to ask for, and what is considered politically meaningful and expedient in contemporary debates about sexuality. Sexuality operates like a looking glass that distorts complex, affectionate, and material life-ways into seemingly coherent, ahistorical registers of human subjectivity and morality.

I hope to expose that in the looking glass of sexuality we are all "other." In other words, sexuality never captures the ways humans actually live; sexuality creates a portrait of classed and gendered normalcy that no one is able to summon, no matter how great their investment in its conventions. Certainly sexuality discourse is globalized (Binnie 2004), but bodies, pleasures, and affection is always simultaneously localized.

\section{A Note on the Politics of Sexuality and Reflexivity}

This is a political project; discussing sexual politics means confronting material debasement and exploitation (capitalist, or otherwise). Assessing limitations to the range and capacity of erotic subjectivity furthers this aim. The question is no less pertinent today than in 1984 when Gayle Rubin proposed in Thinking Sex: Notes for A Radical Theory of the Politics of Sexuality:

A radical theory of sex must identify, describe, explain, and denounce erotic injustice and sexual oppression. Such a theory needs refined conceptual tools which can grasp the subject and hold it in view. It must build rich descriptions of sexuality as it exists in society and history. It requires a convincing critical language that can convey the barbarity of sexual persecution. [1984:267-268]

I offer a critical language here with eagerness, but no small amount of trepidation. Even in this necessary call, Rubin relies on (and obviously deeply influences) a deployment of 
"sexuality" to make coherent what I hope to describe - then disrupt. I argue that another place to begin this denouncement is to further the interrogation of the political economic and historical construction of sexuality, and then use this position to examine contemporary queer anthropology. I make this attempt so that I, too, may more adequately convey and denounce the barbarity of the many forms of persecution and injustice.

Critical inquiries, too, involve questioning closely held beliefs and customs. Even as I introduce the outline of my criticism here, I reflect on the political and material ramifications of relying on sexuality and gender differences as categories of practice to carve more equitable modes of life and gather material support for my communities. An inspection of the practices where I also shape my relations, pursue passions, and join politicized communities is difficult and demanding. So why do it? I defer to Lynn Huffer on this point:

The story of queerness — as a story about madness — begins with the story of a split: a great division between reason and unreason. That split organizes Foucault's histoire — his history and his story—about forms of subjectivity tossed into a dustbin called madness. Queerness is a name we have given to one of those forms. Since the early 1990's, we - queer theorists and loving perverts - have tried to rescue the queer from the dustbin of madness and make her our own. Theory calls this gesture resignification: we have dusted her off, turned her around, and made her into something beautiful.

But, somehow, over the years, the queer has become a figure who has lost her generative promise. She turned in on herself and became frozen into a new, very American identity. And if the transformation itself is to be celebrated, the final freezing is not. Getting stuck in identities that are often politically or 
medically engineered, the queer is drained of her transformative, contestatory power. [2010:1]

Pragmatic encounters with identity and injustice are central to sexuality research and pedagogy in contemporary, liberal education. Students and teachers continually address accounts of injustice and must respond to stupefying horrors enacted under the banner of sexuality. Students are then asked to assist in imagining a world where utopic visions should be suspect, but fervent praxis in aid of human rights, multiculturalism, and for liberal tolerance is ostensibly self-evident and sound philosophy.

Friends, lovers, and citizens are tagged with sexualized and gendered identities. They are then expected to speak with a singular voice. Diverse knowledge and experience is condensed through the prism of social difference, and sexuality is assumed to be the closest position to a more noble truth. Accepting a normative sexuality is supposed to be the best path to social acceptance and social equity. This is a limited vocabulary of socalled "freedom." As Lisa Duggan reminds political activists in her critique of the gay marriage movement:

As the army of lovers and ex-lovers we often imagine ourselves to be, queer people, perhaps more than others, might be expected to see marriage as a much too narrow and confining status to accommodate our elaborate, innovative forms of intimacy, interconnection and dependency. But rather than continue to expand the forms of partnership and household recognition begun by the LGBT movement in the 1970s, the marriage equality campaign has resulted in a contraction of options. [Duggan 2011] 
Engaging a critical study of sexuality may offer ways to remove oneself from these idiosyncratic but terrifyingly reductive margins. Most often, one is obliged to remain in these margins in the name of social stability and in support of a naturalized system of sexual identity. Remaining, frozen there, is not acceptable to me, and thankfully not acceptable to many scholars and writers I reference in this thesis (admittedly, even those I critique for not doing more). John Gray measures our liberal dilemma:

The task of political philosophy is not to give practice a foundation. It has never had one in the past, yet somehow the human species has tumbled on. The aim of political philosophy is to return to practice with fewer illusions. For us, this means shedding the illusion that theories of justice and rights can deliver us from the ironies and tragedies of politics. [Gray 2000:139]

Sexuality is too often invoked as solid ground for social organization and social identity, promising a more truthful understanding of the self and providing pathways to more ethical and just societies, delivering us from "the tragedies of politics."

At the very least, the explanatory power of sexuality assumes a natural assemblage of pleasure and affection and demarcates boundaries for meaningful, moral engagement with others. I now find this assumption deeply troubling. I engage in this thesis study to find other pathways around these constraints for an "army of lovers and ex-lovers." I strive to imagine other possibilities for thinking about political economic materiality of pleasure and affection, and return to practice with fewer illusions. This is challenging. I am reminded of Pierre Bourdieu's concept of doxa in an Outline of a Theory of Practice (1977). Bourdieu summarizes doxa as the status of social knowledge that appears as self-evident, obvious - as knowledge that "goes without saying" within a 
society. It is certainly impossible to address every resulting social difficulty through the practice of critical analysis (shared meaning, it is useful to remember, is how sociality is built). Nevertheless, what I hope to address is why criticisms that already shattered the chimeras of sexuality do not rid us of its doxic charms. In doing so, I hope to honor my confidantes and communities with this study and expand on the hard fought gains the strategic use of sexuality offered to us. Now I hope to demonstrate a pressing need to limit its analytical application for the same reason. 


\section{Chapter 2: Neoclassical Economic Philosophy and the Subject of Sexuality}

\section{Introduction}

In this chapter I examine how neoclassical economic philosophy parallels and affects the sexological discourse of sexuality. "Sexology" is another name for the scientific and psychological discourse of sex and sexuality that began in the late $19^{\text {th }}$ century and continues to today. Neoclassical economic philosophy also began in the late $19^{\text {th }}$ century and continues to today. I aim to understand the historical development of sexuality as a gendered and classed economic philosophy of the body. Sexuality should not be understood as biological or psychological precondition of being human, but instead can be understood as a social order emerging from particular social anxieties and class struggles. I develop this perspective to further contribute to a critical and historical perspective on sexuality. I also offer this as a reply to materialist feminist critiques that contend Foucault did not adequately develop gendered and class-based perspectives in his work on sexuality. I also hope to contribute to an interdisciplinary crossing by applying critical discourse analysis to historical economic literature.

In this chapter, I will first address contemporary concern that critical discourse analysis does not adequately address actual economic literature. I aim to correct that herein. I then examine an economic human subjectivity that emerges in classical political economy. Classical political economists first establish economic precepts of a natural ordered economy, the "free market," and develop the first notions of a gendered (male), rational, economic agent. I address these developments before turning to focus on the neoclassical "revolution" in economic philosophy and its overlap with sexological 
discourses of sexuality. I will argue that this neoclassical revolution deeply parallels and affects the sexological invention and construction of sexuality. I do not imply that neoclassical economic literature caused the development of sexuality. I will accentuate, though, that sexologists construct sexuality with similar terms, ideals, and a remarkably similar subjectivity. I will note how sexuality can be understood as a gendered and classbased capitalist economic philosophy of the body. Contemporary criticism of sexuality rarely accounts for parallels between the historical construction of sexuality and the historical construction of human subjectivity in economic literature. I hope to fill in some of this missing account.

I am heavily indebted to the work of Lawrence Birken for first bringing the parallels between economic history and sexology to light in Consuming Desire: Sexual Science and the Emergence of a Culture of Abundance [1988]. Despite the brilliance of his work, Birken too hastily dismisses Foucault's emphasis on sexuality as social control. I will advocate that the construction of sexuality should be understood as a virulent class struggle over bodies and pleasures. Sexuality is developed to institute a vision of an economical and proper use of pleasure and affection against a normative sexuality that is gendered and classed. This critical examination will further illuminate sexuality, therefore, as an economic-capitalist discourse primarily concerned with instituting the role of a naturalized, patriarchal, and rational masculinity (first developed in classical political economy) but expressing the unlimited desires and pleasures that must be judiciously managed by a normative, upper-class male. Only "he" is capable of such discernment. Intensification of interest and surveillance of "deviant" and "perverse" bodies, pleasures, and affections are rooted in these class-based social struggles and take 
pernicious form in the beginning of the neoclassical economic era during the late $19^{\text {th }}$ and early $20^{\text {th }}$ century.

Sexuality is a rubric of bourgeois desire for political and economic rule, and further justification for inequitable economic conditions. Yet the neoclassical era also represents a radical expansion of economic opportunity, and the development of individuated ideals of desire and pleasure for all consumers. I want to show that the sexological development of sexuality reflects this social transformation, but quixotically also serves to manage the anxieties this social transformation produces. Sexuality is maintained as a master narrative to silence and subjugate other knowledge about the pleasures and affections of the working classes, migrating classes, women, and other urban denizens. Sexologists work feverishly to catalog and document sexual difference, but also continually assert a classed and gendered sexual norm, even as its actual possibility seems to recede further and further away from a material reality.

\section{Parallel Criticism: Critical Discourse Analysis and Economic Literature}

Economic philosophies pertain to the "economy" but also offer insight into the paradigmatic intellectual and social climates of their time. Economic philosophies provide a looking glass into the prevailing concerns and conditions of material life. For this reason I attempt to unbraid a small section of the tightly wound rope of economic philosophy to understand the establishment of a classical and neoclassical economic subjectivity. Social constructionist theories of sexuality account for changes in social institutions, variations in ideas about human subjectivity, and map parallels between discourses. In contrast, some cultural criticism offers sexuality as a pathway to economic 
and social freedom, and a way out of capitalist repression. This model of liberation follows from psychological discourses of sexual repression (Freud 1975; Reich 1963; Marcuse 1966).

Debates in literary and cultural theory critically engage economic terms. These debates employ and deconstruct numerous tropes, concepts, and metaphors shared in classical and neoclassical economic philosophies (e.g. economy, libidinal economy, circulation, desire, consumption, energy, and capitalism). Analysis of the economy and economic literature, however, mostly run in separate veins. It is as if two worlds exist: one in which economics is performed and one in which economics is critiqued (McCloskey 1998; McCloskey et al 1988).

Jack Amariglio and David F. Ruccio reflect on the seeming incommensurability of economic criticism and economic practice when recalling a 1990's conference of cultural theorists and academic economists (Amariglio and Ruccio 1999:381-400). The conference attendees attempted to seek mutual understanding and interdisciplinary knowledge about active terminologies. They attempted to share new concepts to further enable Marxist and political economic critiques of the existing economy. The attendees asked how criticism of globalization and economic crises could proceed from shared critical strategies in both cultural study and economic theory. This conference instead ended with head scratching and frustration (1999:381-383). By attending the conference, participants hoped to avoid this type of disciplinary isolation, but it still emerged in the end (1999:385). In reflection, Amariglio and Ruccio narrate three important points that I consider before applying critical discourse analysis to economic literature (1999:381$385)$. 
First, economic debate in the so-called real discipline (academic economic departments) and cultural criticism do share theoretical orientations about the dilemmas of language and representation in the history of economic thought (for example: value, price, money, culture). This should be recognized more often. Second, both neoclassical economists and cultural critics establish and re-establish certain essentialisms in their work (establishing "capitalism" as necessarily pervasive and determining, tropes of commodity circulation, and tropes of circulating desire). In other words, both rely on certain naturalized ideals about economic human subjectivity to advance their arguments. Finally, Amariglio and Ruccio find more shared ground between economists and critical theorists: they both introduce a "desiring body" in political economic critique, and both share an interest in the subjectivity of the economic "man" (Amariglio and Ruccio 1999:385-394).

I detail these points to demonstrate that economists and cultural critics retain a commitment to a similar pleasure-oriented human subjectivity. They also address the subjective meaning of fulfilling desire (albeit to radically different ends). Both economic philosophy and cultural criticism narrate strategies for more effectual economic thinking and political practice. Economic literature is perhaps not the "sexiest" literature to examine but, with a bit of irony here, it may be the sexiest literature of all; sexologists import economic epistemologies to help construct "sexuality."

Popular parlance coins economics as "the miserable science" because economic philosophies must contend with material life and scarcity. Sexuality is often envisioned with quite opposite effects. Sexuality is popularly understood as a commentary on pleasure and affection and the capacity of the human body to relish pleasurable 
experiences. In short, sexuality and economics seem separate, distinct, and incompatible but they are not. Relating sexual pleasure to economics is often considered unromantic and ruinous to sexuality (Tratner 2002; Baumeister and Vohs 2004; Francis 2008; Regnerus and Uecker 2011). This supposed comparative limitation aroused my suspicion and animates my study. Eve Ksofsky Sedgwick notes that cultural critics too often create paranoid readings of texts (Sedgwick 2003). I do not want to make this error. I offer a type of reparative reading that Sedgwick identifies and advocates: point out the nourishing surprises and hopes that may be generated in reviewing and claiming "sustenance from the objects of a culture — even of a culture whose avowed desire has often been not to sustain them" (Sedgwick 2003:150-1). Envisioning sexuality as an economic philosophy is reparative in this regard.

I propose sexuality as a fundamental economic philosophy of the body. This does not diminish a vision of pleasure and affection as necessary and meaningful, but instead I envision a new comprehension of sexuality and economic history, and in turn, other ways to think about human subjectivity. I now turn to examine the human subjectivity that emerges out of classical political economy before devoting the rest of this chapter to parallels between neoclassical economic thought and sexological construction of sexuality.

\section{Classical Economic Subjectivity: Male, Rational, and Self-Interested}

Presaging neoclassical economic philosophy, moral philosopher and classical political economist Adam Smith recognized the realities and dilemmas of economic systemization. He expressed great concern for potentially debasing conditions of labor 
and the development of ignorance among laborers. He expressed apprehension about capitalist money men being the "scariest, nastiest" creatures in society, if not nature (Pack 1991:147). Smith's An Inquiry into the Nature and Causes of the Wealth of Nations (1909 [1776]) still presented a marvelous vision of the laboring human. The skill, flexibility, and productivity of the economic human are epitomized by a theory of a natural division of labor. He marveled at this supposed natural organization of wage labor. He celebrated the ongoing drive he conceived as simultaneously economic selfinterest and, curiously, self-love and social order (a theme Karl Marx later develops and criticizes). Adam Smith understood the economy as an expression of natural law and order. In similar ways, early classical economic philosophers drew deeply from the developing themes in the natural sciences.

Natural sciences detailed the body as well-organized and with specialized detail, but functioning in a physiological whole (Bicchieri 1988:104). This knowledge stood in stark contrast to the supposed barbarism of past ages. Economists begin to detail the market in similar terms. The economy is the epitome of good human work, but still expressed revealed natural orders. Much is gained by those who act in their natural selfinterest (Smith 1909). Smith admits, however, that his new science stemmed from his moral sentiments. In this regard, any variance that refuted the naturalized economy disrupted the "mental harmony" of the economist as moral philosopher (Oakley 1994:19). It useful to note that Smith's approach to the economy and capitalism "was strongly psychological and he emphasized the subjectivist aspects of its procedures" (Oakley 1994:19). The economist aimed to reduce any disruption to this preconceived vision of harmony. What did not fit could, and should, be explained away. For Smith, and other 
classical thinkers, the rule of self-interest revealed the interest of every citizen. This symmetry led to more efficient markets, more refined divisions of labor, and greater wealth for all. The invisible hand guided liberty, encouraged self-regulation, and advanced freedom as one and the same.

John Stuart Mill later arrayed personal freedom as a buffer from a potential tyrannical state in his 1859 treatise On Liberty (1996). Mill argued that human subjectivity naturally strived for liberty. The guiding ethic is a Classical and Utilitarian one: moral virtue is determined by consequences of actions. Utility is the maximization of happiness through appropriate action. Human subjectivity acting in self-interest is already a benevolent social force. Classical economist David Ricardo developed a labor theory of value and imagined the economic human subject in comparison to "noble savages" acting in their economic interest (1960 [1821]). Modern people are similarly noble, and regardless of historical progress the self-interested subject still must contend with some type of scarcity. Accordingly, the economic human competes for scarce resources, even in a society of abundance (Ricardo 1960). The conditions of wage labor expressed natural principles of order. Any questioning of miserable labor conditions is in the unenviable position of questioning natural principles.

Classical economists like Smith, Ricardo, and Mill inscribed an estimation of rationality throughout their economic literature. The moral philosophy of economics is the natural order of the market, and suggested a benevolent absence of conflict between self-interest and social interests. Smith, Mill, and Ricardo's economic philosophies did not require a theory of mutual or personal affection, only the concept of utility as a maximization of pleasure. But, all was not entirely well in this model of rational and 
fruitful abundance, and self-interest as social interest. Laborers seeking wages were both necessary but a problem of population management and stoked fears about scarce resources. Wage labor also stoked fears about a declining patriarchal family household: "those who had fared well in the old patriarchal order were frightened by its looming obsolescence, but even those whose stood to gain were threatened by new forms of economic insecurity" (Folbre 2009:138-139). This patriarchal obsolescence was partly mitigated by the emerging economic focus on a gendered and classed subject: the individual male at the center of the classical economic philosophies even though women and youths were also working throughout the economy (Folbre 2009:126-128).

Social theorist Jeremy Bentham (1961 [1789]) further developed a theory of utility. He proposed a felicific calculus to comprehend a seeking of pleasure and avoidance of pain. Bentham argued this calculus of pleasure and pain is the core of human subjectivity. He seemed to doubt the naturalizing totality of earlier political economic theories and he noted deficiencies in the concept of natural law: since a requirement of utility accorded the greatest happiness for the greatest number, some human subject must be left out of this greatest number. But Bentham's portrait of subjectivity posed the human as a rational agent and determined the social body as a necessary collection of humans acting in their self-interest (1961). Accordingly, humans recognized the truth of who they are through judicious economic activity. For Bentham, humans knew this to be naturally true and any attempt to undermine his theory of economic utility is explained away as a quirk of utility. Pleasure is sought and pain is avoided — there is no other subjective way. 
A distinctly gendered male economic rational subjectivity was first commented on by John Stuart Mill and Adam Smith. Adam Smith bestowed this man with little benevolence, however, by famously noting that the baker and butcher did not bake and butcher for their own pleasure but for self-interested reasons (Smith 1909:106-112). Mill offered a similar sentiment in the essay "On the Definition of Political Economy, and on the Method of Investigation Proper to It" (1874 [1844]): if it was not for man seeking profit there would be no social order and no political economy of which to speak. A noble man seeks profits, and employs every opportunity to do so. The seeking of profit, the recognition of self-interest as social interest, and the valorization of the pursuits of pleasure are gendered as naturally male pursuits. Mill furthers this distinction when noting man is a "being who desires to possess wealth, and who is capable of judging the comparative efficacy of means for obtaining that end" (1874:v.38). Importantly, the accumulation of wealth and the establishment of property rights were generally assumed to be male-only social domains. Women and men also advocated for female inheritance rights, but widespread development of new laws was not established until the 1850's (Chused 1983). The classical economic subject is decidedly male and in the pursuit of wealth.

Perhaps the most famed of classical political economists is Karl Marx. He envisioned evolutionary economic orders advancing through historical eras. In Capital, Marx (1990[1861]) critiqued capitalism's bleak conditions for laboring classes. He argued that society is misled by the mystifications of capital. Labor value, a capitalistic necessity, occluded a real economic subjectivity with an alienating capitalistic one. Wealth is derived wealth from a worker's estranged labor. This is the delusion that 
capitalism offered according to Marx. Plainly, a worker will never earn what labor is worth. The commodity produced is the desirable "object outside us" and desire expands far beyond what is necessary for survival (Marx 1990:13). This illusion distanced workers from their own vital life-force (1990:31-32). Real pleasure for the working class will always be deferred. Real pleasure can only be attained when workers are not alienated from their own productive brilliance and the products fashioned from their own hands. The consumption of commodities stands in the place of actual fulfillment. Marx's "commodity fetishism" explains the seemingly religious relationship between commodity and worker that results in an abysmal false consciousness. This relationship inscribes a "social hieroglyphic" that demands critical translation (1990:32). For Marx:

Culture really has only one parent, and that is labour-which for him is equivalent to saying, exploitation. The culture of class society tends to repress this unwelcome truth; it prefers to dream up for itself a nobler progenitor, denying its lowly parenthood and imagining that it sprang simply from previous culture, or from unfettered individual imagination. [Eagleton 2003:8]

Marx envisioned asymmetrical social and political conditions advancing toward continual economic disequilibrium - a constant social crisis. This vision of the economy and the human subjectivity contrasted with Smith, Mill, and Ricardo and even at their most pessimistic they did not compare to Marx's withering critique.

Marx developed a potent and enduring conception of class analysis. He illuminated the politics of economics that ordered classes for profit for ruling classes. He engaged the ideals of revolution and resistance in significant ways that continue to guide discussions of class-based inequalities today. For Marx, history is the record of class 
struggle. History remains dialectically material and teleological. The end of history is a communist utopia emerging from total societal transformation (Marx and Engels 1967 [1888]). Because the natural subject of the economy is labor, labor alone contains seeds of resistance to ideological abstractions. But ideology entrenched class, justified the extraction of surplus labor value, and limited class consciousness and solidarity. Only the multitude of these productive forces overcoming the ideology of capital produces the necessary communist revolution (Marx and Engels 1967). For Marx and colleague Friedrich Engels, "Life is not determined by consciousness, but consciousness by life" $(1977: 155[1845])$.

Life is class struggle until the end of history. Until then the noble male worker passes life resisting capitalism's shifting rationales for dismal class conditions and capitalism's uncanny flexibility in disguising his natural solidarity with other workers. Marx and Engels, despite their productive relationship, offered very little on the totality of workers in the public sphere and less in regard to gender; they emphasized the male subject like other classical economists. They offer even less on the strenuous, continuous, and gendered work of feeding, clothing, cleaning, and caring for workers in the domestic sphere. Nancy Folbre (1991) critiques this conception of the "unproductive housewife" as does Ann Crittenden (2002) when she asks why mother's work "was disappeared" through the social invention of the unproductive housewife and subsequent devaluation of domestic work of all kinds. They both answer the question by focusing on the development of rational economic "man" whose wage labor is imagined as the sole and proper source of value. Interestingly, Crittenden notes that women "won" certain legal 
rights to custody of their children in the mid- $19^{\text {th }}$ century, but at the cost of being perpetually isolated and devalued in the domestic sphere because of it.

I detailed these classical economic philosophies to establish how prior to the neoclassical turn, economists already established an authoritative and prevailing human subjectivity. This human subject is gendered as male. He is a rational and self-interested social actor. This self-interest presented no social dilemma for these classical economists, though, because rational self-interest was already goodly and benevolent social interest. The male, rational economic subject could do no wrong. Any behavior was already socially interested behavior. This economizing male was self-interested toward pleasure and in avoidance of pain. Despite this celebrated vision of economic similitude, all is not entirely well as Marx noted. His vision of economic subjectivity is decidedly gloomier and haunted with exploitation behind closed factory doors (and this, in reality, included males, females, and youths of all ages). Despite this, the celebrated classical economic rational self-interested male pleasure seeker prevails to this day in certain degrees. Neoclassical economic philosophy builds on this vision, despite the transformations in an urban landscape offering very different material evidence of human life. I now devote the remainder of this chapter to assessing the neoclassical economic revolution.

Neoclassical economists import the rational, gendered, self-interested, pleasureseeker and build an economic subject with all these characteristics, but with distinctly new additions that reflect a new accounting of desire in a newly realized consumer economy offering unlimited pleasures. Consumption becomes the central focus in neoclassical philosophy and is guided by male consumers operating with a distinctly psychological rationality and confronted with rational choices to make (Nelson 2006:18- 
21). This is the neoclassical homo oeconomicus. After detailing these subjective additions, I will show this economic subjectivity parallels sexological construction of another type of human economic subjectivity—sexuality.

\section{Troubling Bodies: Neoclassical Economic Philosophy}

The neoclassical human subject is embedded with earlier classical political economic theory of natural orders. The neoclassical human subject remains an entirely natural creature, expressing little evidence of social conflict or scarcity. Neoclassical economic subjectivity combined theories of bodies striving for pleasure and avoiding pain, measured by an internal felicific calculus, and exercised through judicious economic activity and consumption. This bestows an optimistic vision of human subjectivity despite being crafted in the science of scarcity. Despite any grave economic concern offered by classical political economy, naturalized ideals of economic philosophy ameliorated much of it. The economic order was natural, after all.

After this neoclassical turn in economics in the late $19^{\text {th }}$ century, all males of a certain standing are assumed to behave in fully rational ways, because of their effort to maximize personal utility, and with a new world of markets and commodities at their fingertips (Nelson 2006:18-22). All necessary information for rational choice is assessed by this economic agent, but hemmed by scarcity of desirable goods. This is professed by neoclassical philosophy to still be in accordance with natural laws; self-interested behavior is still good for all.

Neoclassical economist William Stanley Jevons (1957[1871]) further refined the concept of utility as a composite of characteristics dependent on various human 
circumstances and human needs. Importantly, and central to the neoclassical revolution, Jevons instilled commodities into the felicific calculus and discerned the weighing of price and the consumption of commodities as an expression of pleasure warding off a now distinctly psychological type pain. Accordingly, Jevons' theory of value determined happiness as a necessary scaling of marginal utility through consumption. He notes that "perhaps our attention is more fixed on the utility which we desire to secure than the disutility from which we are trying to escape. Yet it would be difficult to deny that pain constantly attends pleasure" (Jevons 1965:9 [1905]). This scale proposed decreased satisfaction with every consumptive act — a scale of diminished returns weighed on every pleasurable act of consumption. Jevons avoided the complexities of individual expressions of utility. He quotes an English economist to note that "no man is satisfied with so limited a range of enjoyment" (Jevons 1965:8). He instead composed the rational man as an average man to base his theory and this average man. Economic humans (average "men") are happy subjects to the natural phenomenon of maximizing pleasure. Of course, these average men were not the average laboring men, but the average upperclass men of his time concerned with pursuits of pleasure. He makes distinct that even "immoral or criminal" objects have utility, and only ignorance would predicate utility being hurtful, but this is still utility if one is ignorant of the hurtful part of the thing being desired (Jevons1965:12). Desire is the key determinant of utility in this sense.

Contemporary feminist economists contest this gendered and classed version of economic subjectivity (Duncan and Edwards 1997; Strober 1997:11). Kurt Rothschild also notes that a reluctance to abandon this model in contemporary economics is fueled by fear of being closer to the "fuzzy reality of man and society" (Rothschild 2001:450). 
The fuzzy reality of man and society also realizes that no man, no human, lives in a gendered isolation. Classical economists established the gendered subject, and neoclassical economic thinkers continued with the assumption that all human economic activity pertained to male pursuits, despite the overwhelming and obvious evidence that women worked in the private and the public sphere. This is especially the case for lower and working class women who worked in both spheres. Folbre discusses how women were paid less than half of men during this time and "this discrepancy was explained in both natural and moral terms: women belonged in the home and should remain there" (Folbre 2009:135-136). Economists' notions of separate, pure spheres of economic life composed another economic fantasy that avoided more of the fuzzy reality of material life.

Neoclassical economist Marie-Esprit Lèon Walras granted human subjectivity a communal "we" in Elements of Pure Economics (1954[1877]). But he continued to theorize human subjectivity as a rationally consumptive pursuit of utility maximization in a perfectly competitive market. Walras thus theorized a "purity" of equilibrium in the market. This theory proposed that prices fixed to utility (an early type of consumer demand) in a setting of perfect competition. Economic purity now expressed nothing less than the natural truth of scientific physics; the laws being formulated in the natural sciences seemed perfectly suited for the economic rationalities offered in neoclassical economics. Economic systems now guided natural energies and offered social expressions of natural physical laws, as well as the bodily ones offered in earlier political economic theories. "Pure" economics is the mother tongue of the neoclassical economic revolution, and the tenets are still used today (Osteen \& Woodmansee 1999:22-25). 
Neoclassical economists were not immune to the realities of $19^{\text {th }}$ century material reality. Despite idealistic visions they too were, to a degree, participating in a type of anthropological accounting of the economy, as well theorizing its natural perfection. Carl Menger offered that the human economic agent also struggled with forces of deprivation and overstimulation in capitalism. This compounds a theory of utility and rationality that delivers mostly subjective joy and satisfaction. In the 1871 text Principles of Economics, Carl Menger invoked these extreme economic situations to demonstrate how humans act within a marginal utility of diminishing satisfactions (1981[1871]). This is the beginning of a utility that exists in accordance with falling satisfaction: a diminishing rate of marginal utility. He even goes so far to note that "non-economic goods, therefore, not only do not have exchange value...but not value at all, and hence no use value" (Menger 1981:118). In this sense, only economic commodities can be valued in any real sense.

Menger's ideal presented another diminution of the domestic sphere, and disregarded other types of economic exchange. Menger then determined that rational economic men "will prefer pleasure of longer duration to pleasures of shorter duration, and with the same duration, pleasures of greater intensity to pleasures of less intensity" (Menger 1981:123). Consumption is the ultimate point of the economy and of a pleasurable life. The consumer of fine things with fine tastes is the radical new individualized center of the consumptive economy. The holism of production erodes into this individual consumer. The neoclassical system thus "implied that desire was the only criterion for social agency" (Birken 1988:35). Unfortunately this does not carry over in the same way to sexological discourse. Desire in the sexological scene comes to represent a deviant distortion of social agency because of the multiplicity of possible desires. 
Menger also focused on varying human needs, subject to the individual and not solely based on objective forms of universal pleasure. Only human desires dictate any value as "human knowledge of the different degrees of importance of satisfaction of different needs and of separate acts of satisfaction is also the first cause of differences in the values of goods" (Menger 1981:128[1871]). This subjective theory of value marked a further transformation in economic philosophy. And Menger provided further philosophical sustenance for the neoclassical model of consumption as only necessary locus of economic energy. Menger also imagined this capitalistic order as an evolutionary form of development (he termed it spontaneous). The economy accordingly was an evolutionary order and thus subject to some scarcity and conflict. His philosophy then composed a subjectivity that was decidedly psychological in its orientation, and composed of individual wants, needs, and desires but hemmed by this evolutionary realization that all could not be met. Bentham's calculus first provided the framework for a psychological wedding of desire with utility (Birken 1988) and Menger built his philosophy out of this.

\section{Troubling Bodies: Neoclassical Economic Philosophy and Sexology}

During the late $19^{\text {th }}$ century, hundreds upon thousands of bodies were arriving in urbanizing and industrializing centers to pursue work. This sparked another intellectual project: sexology. During the neoclassical economic transformation, sexologists also constructed a portrait of human subjectivity that paralleled economic philosophy in startling and, I suggest, not coincidental ways. Despite the marvelous testaments of economic social order in classical and neoclassical economic philosophy, the urban 
spaces were teeming and chaotic. I compare the themes within sexology and neoclassical philosophy to demonstrate similar constructions of subjectivity. Sexuality should thus be understood as a $19^{\text {th }}$ and early $20^{\text {th }}$ century economic philosophy of the body. Sexologists also work, though, to disrupt and subjugate other knowledge of pleasure and affection emerging from the same economic milieu.

Sexologists Sigmund Freud, Havelock Ellis, Richard von Krafft-Ebing, Magnus Hirschfeld, and Iwan Bloch all developed a sexological subjectivity during the 19th and 20th century with the belief that they were discovering pure, natural essences applicable to all human beings. Krafft-Ebing's staggeringly influential work Psychopathia Sexualis (1965[1894]) composed human sexual subjectivity as a striving male "achieving" a natural purity in heterosexuality (after a few perverted bumps in the road, of course). Females, on the other hand, were less striving, at least not in the same sense: "A particular species of excessive sexual urge may be found in females in whom a most impulsive desire for sexual intercourse with certain men imperatively demands gratification" (Krafft-Ebing 1965:5). Sexuality is the terrain of a male, individual, rational pursuit of pleasure in a changing social milieu. This model man is the mythologized "benevolent patriarch" within economic subjectivity (Strassman 1993:5468) and forms the foundation of sexologists' construction of sexuality. It is useful to ask how sexologists composed an ideal sexuality, all the while locating and mining evidence of perversions, sexual deviations, and cultural anomaly. Sexologists gathered evidence that pointed to a vast and rich milieu of sexual cultures, yet a natural, stable, and rational subjectivity is simultaneously constructed to render any other interpretation moot. 
A classed and gendered portrait of this economic milieu is offered by John D' Emilio in "Capitalism and Gay Identity" (1997). European and American household economies underwent major alterations during the 19th and 20th century. The industrial capitalist mode of production transformed the local, agriculturally based household member into an urban-bound wage earner. D'Emilio emphasizes that through proletarianization, urbanization, and the expansion of wage labor, an "ideology of family life and the meaning of heterosexual relations" are profoundly altered (D'Emilio1997:170). He notes that household economies relied on the reproduction of new members for agricultural and household labor. Sexual expression was accordingly coupled to marriage. In earlier Puritan American communities laws restricted anyone from living outside family households (D'Emilio1997:170). A notion of "heterosexual expression [as] means of establishing intimacy, promoting happiness, and experiencing pleasure" first develops within the demands of an industrializing economy.

This economy also provided the space and conditions for identities based on same-sex sex affection to develop (D’Emilio1997:171) as well as other gendered, classed, and diverse forms of pleasure and affection. In other words, sexual behavior that constitutes identity today did not always ground identity in the past. Jonathan Ned Katz notes that heterosexual relations are not even yet "heterosexual" in the mid-19th century. The very concept of hetero- and homo- distinctions based on sex acts, not to mention identities, are not coined until writer and social reformer Karl Maria Kertbeny includes them in a private letter in 1868 (Katz 1997:177). It is essential to note this decade is also the marker of the neoclassical philosophical transformation. 
D'Emilio and Katz's historical analyses point to a historical emergence of a "normal" sexuality. They remind readers that heterosexuality was constructed and implemented to help interpret and re-organize social life undergoing these profound material transformations. Despite the rapid implementation of heterosexuality as normal during this time, it carried the stigma of deviancy as "morbid perversion" well into the early $20^{\text {th }}$ century (Katz 1997:177-178). That is to say, sex based on heterosexual pleasure could also be a moral perversion if there was too much of it. This idea eroded as other deviancies piqued the interest of sexologists. Foremost, though, sexologists grappled with composing a philosophical basis for a universal and natural theory to ground their discoveries of divergent sexual cultures and divergent forms of pleasure and affection. They "discovered" sexuality.

Sexologists, as much as economists, were observing radically different ways of life (and sexual cultures) within the industrializing and urbanizing spaces, and they both attempted to account for this diversity with an economic subjectivity in mind. As Iwan Bloch considered in the disturbingly named Anthropological Studies in the Strange Sexual Practices of all Races in All Ages: Ancient and Modern, Oriental and Occidental, and Primitive and Civilized (1933), almost every person has variations of desire and he worried that "sexual relations usually considered normal, as in these too we can demonstrate a progressive need for stronger stimulant" (Bloch 1933:167). This is strikingly similar to the estimation of an economic diminishing utility. Apparently, though, this is more of a problem among "all places in which great numbers of people are crowded together furnish conditions conducive to the genesis of transgressions and aberrations of a hetero- and homosexual character" (1933:176). Importantly for my 
emphasis on class Bloch continues to note that in "worker's tenements, where often a whole family lives in one room, the children early have an opportunity to witness scenes of the grossest vice, especially where there are also lodgers" (1933:176). Bloch continues to cast his net even among the middle and upper classes, by noting that "sexual perversion, especially of a homosexual nature, occurring later in life, can be traced to the years spent in boarding school" (Bloch 1933:178). Bloch ignored that there are few other options in boarding school for other conduits of pleasure and affection, but he noted that at least these are artificially fostered compared to other more inborn perversions, like among basically every other culture and "race" on earth which he details with relish.

Like Jeremy Bentham, who examined concerns about the ironic deficiencies of natural laws, sexologist Richard Von Krafft-Ebing surmised that natural sexual and gender deficiencies required political intervention to achieve a more natural state of humankind. Krafft-Ebing proposes in Psychopathia Sexualis (1965 [1894]) that all sexual abnormalities must be rooted in a similar pathological-psychological continuum and must be confronted in an attempt rehabilitate resulting immoralities. Sexuality, Krafft-Ebing noted, is the "most powerful factor in individual and social existence" (1965:3). Bentham argued that any effort, thoughtful or otherwise, to discount or dismiss the principle of utility among individuals is futile - for any effort to diminish its truth is evidence of its natural truth (Bentham 1961:19-21[1789]). For Krafft-Ebing, any dismissal of the power of sexuality over men dismissed a necessary moral heterosexuality. He argued that moral heterosexuality was necessary for taming animal passions. Without it there is no foundation for civilization. Sexual subjectivity holds the seeds of civilization and chaos. His construction of normal sexual subjectivity required manly, judicious, constant, 
felicific oversight, just like the economic subjectivity of classical and neoclassical philosophy. Women were clearly of less concern, as Krafft-Ebing decided women are by "nature not as sensual and certainly not as aggressive in the pursuit of sexual needs" (1965:262[1894]). In either case, even love is suspicious because "purely sensual love is never true or lasting, for which reason first love is, as a rule, but a passing infatuation a fleeting passion" (Krafft-Ebing 1965:7). Sensual pleasure was to be limited as it instigated the very desires that were already coursing through psychology and sexology, borrowed from neoclassical philosophies, and paralleled new ideas about an economy filled with consumer goods that must all be desired. The economy now depended on it. Desire may be natural, but is also naturally dangerous without a gendered and classed intellect to govern it.

For many early sexologists, rational and judicious men provided the necessary and proper oversight of sexuality. The difference between men and women is stark: "In the sexual demands of man's nature will be found the motives of his weakness toward women. He is enslaved by her, and becomes more and more dependent on her as he grows weaker, and the more he yields to sensuality" (Krafft-Ebing 1965:9). This resistance to sensuality was assumed to be a natural duty over less-worthy men, women, and children. If men are incapable or unwilling, then women may play some role and prove their "worth." Ann Laura Stoler notes how the "triumph of the rational bourgeois man in colony and metropole" rendered both women and non-Europeans into a category governed not by rationality, but by animal passions (1995:128-130). Yet women were still expected to oversee men of their "race" from mingling with native women. This certainly illuminates sexual subjectivity as a type of social control; as Stoler remarks on 
the colonies, "more than half the European male population were cohabiting out of wedlock with native women in the late $19^{\text {th }}$ century" $(1995: 129)$. These colonial encounters produced social pressures at home that roused sexologists' efforts.

This pattern offers a critical insight into the sexologists' effort to account for all sex behavior coordinated by a single, universal, and naturalizing (and anthropological logic in Iwan Bloch's cases): “Time and again, one finds sexological writing —all the way from the 1890 s to today — seeking to produce some everlasting truth about the sexual capacity of human beings" (Bristow 2011:15). Accordingly, a rational man acting in his own best interest while searching out and weighing the pleasures in life, but with diminishing returns, provides sexology with a compelling psychological composite to building the sexual subject. In addition it offered sexologists a normative model from which to theorize all other pleasures and affections as perversion, inversions, and deviations.

So, despite, the newly available bodies, desires for commodities, evidence of various pleasure and affections, sexologists and economists were both keen to develop an interior, psychological world to justify limits and order on the dissonance, diversity, and contradictions in material reality. John F. Tomer details how the economic man remained “self-interested, rational, unchanging, separate, and unreflective" (2001:281). His assessment could just as well be detailing the sexological development of normative sexuality.

Sexologists demonstrate an intense interest in punitive and rehabilitative sanctions for sexual, laboring "others" as much as they demonstrate naturalist interest in creating taxonomies of sexual perversion and normalcy. Effort to comprehend and systematize 
behaviors, cultures, and acts is not a benign $19^{\text {th }}$ and $20^{\text {th }}$ century naturalistic exercise. Accordingly, sexologists do not simply hope to find order in the $19^{\text {th }}$ and $20^{\text {th }}$ century urban landscape; they endeavor to enforce a capitalist social order as well. Neoclassical economists, at least, argued the economy was a natural order; sexologists went one further and worked to warn, display, and cajole upper-class men and some women into a perceived natural order that was apparently falling apart before their discerning eyes. As with any attempt at social order and control, these efforts have mixed results.

Sexologists like Krafft-Ebing (1965[1894]), Bloch (1933, 1936[1909]), and Hirschfeld (2000[1919]) already speculated a sexualized capitalistic human subject when they developed a sexual subjectivity. They enforced a masculinist, familial, and psychological framing of the sexual subject through the newly refined category of sexuality. The sexological "scientific" endeavor can and should be understood as a class struggle. The master narrative of sexuality subsumes other pleasures and affections that, as Katz (1997, 2001) and D'Emilio (1997) noted, were as "natural" as the environments they were taking shape in.

Differences in class standings made bodies available for sexological discernment. The evidence of "perversions" was ascertained by the upper and bourgeois intellectual classes simply through observing the different cultural traditions and practices of the working classes. This was all the evidence they needed to recoil in horror. Police, reformers, doctors, and politicians were armed with the incipient knowledge from sexological discourse to justify sanctions, class punishments, and other efforts of confinement or rehabilitation. Of course "deviants" and those who occupied the upper classes were not immune to each other. Upper classes certainly mingled in the blue hour 
of twilight and in the back alleys of clubs, bars, and other establishments of so-called illrepute.

The intellectuals of modernity were deeply concerned with the ability of social science to find parallels to the "laws" of natural science (Hobsbawm 1975) as much as economists. Sexologists imagined that understanding natural foundations bodily and behavioral differences (which would encapsulate gender differences and sexual behavior in this time) were the keys to unlocking and controlling the diverse sexual phenomena observed and reported in the urban landscape. All the while, upper class and bourgeois intellectuals were already haunted by notions of their own failed moralities. This duality is described by Eric Hobsbawm in The Age of Capital 1848-1875:

The duality of matter and spirit implied a hypocrisy which unsympathetic observers considered to be not merely all-pervasive but a fundamental characteristic of the bourgeois world. Nowhere was this more obvious, in the literal sense of being visible, than in the matter of sex. This is not to imply that the mid-nineteenth-century (male) bourgeois (or those who aspired to be like him) was merely dishonest, preaching one morality while deliberately practicing another, though patently the conscious hypocrite is more often to be found where the gap between the official morality and the demands of human nature is unbridgeable, as in this period it often was. [1975:232-233]

Efforts to bridge the gap between the so-called private moralities and the public experiences of bourgeois male citizens certainly stimulated the discourses that took sex as the object of inquiry. Sex, and the bodies performing its variations in streets, bars, clubs, balls, and houses of prostitution (Katz 1997) provided the empirical evidence necessary, and indeed a moral necessity for gentlemen and gentlewomen to support sexual and 
economic sanctions, whether they participated in "deviant" sex or not. This class struggle fueled sexual sanctions and punishments, and these were imposed on diverse working class sexual cultures in cities and towns across the US, Europe, and the colonies and under various guises (Boag 2003; Stoler 1995; Jackson 1996; D’Emilio1997; Halperin 1990; Katz 1997, 2001; Chauncey 1994; Rupp 2002; Faderman 1991). It is evident in Bloch's assertion that many alarming possibilities are instigated by the "sexual impulse." But these sexual potentials can be judiciously resisted and elevated from the "transient" and "casual" to limit the poisoning of the "amatory life of our time; let us destroy all the germs of degeneration, and let us imprint upon our sexual conscience three wordshealth, purity, responsibility" (1936:765[1909]).

Certainly pleasures and affections and bodies are organized and managed in other places and other times. But sexuality is a unique construction: sex as a behavior or simple capacity for pleasure is transformed into ontological categories of personhood and deviancy during the late $19^{\text {th }}$ and early $20^{\text {th }}$ century through sexological efforts (Foucault 1978; Cameron and Kulick 2003:19-24; Seidman 2003; Rubin 1984; Halperin 1990; Weeks 1991; Katz 1997:177-180). This emergent discourse should be understood as precipitated by class anxiety and class struggle. I remind my reader that sexuality is highly suited for class control because the rationale that discursively operates within it already incorporates a class-based economic subjectivity. Yet, sexuality was socially imagined to be distinct from economic consideration. Feminist thinker Margaret Jackson attempts to understand the sexological literature of this time and comes to a similar conclusion with gendered implications: 
Sexology was about much more than legitimizing myths; it was also about constructing a model of sexuality which purported to be objective and scientific but in fact reflected and promoted the interests of men in a sexually divided society. [1987:52]

Similar to racial typologies also circulating (Somerville 1994) during this new economic order, the supposed natural laws for bodily and behavioral differences reinforced classed political concerns and a maintenance of power through the new vector of sexuality.

Sexuality came to serve as a key determinant in understanding people's relation to nature, to each other, and to the social whole. Sexologists offered then a vector for determining "truth" about pleasure, affection, and agency divorced from economic consideration (Birken 1988:7). Sexuality encompassed a new phase of naturalized individualism but also compatible with technologies that enforce certain relations and affections. "In this context, sexology takes on a particularly titanic significance because it appears as the last line of defense against a universal democratization and dissolution of the social order" (Birken 1988:13). After Birken establishes this point, he retreats by critiquing Foucault for a failure to recognize the "two-sided and contradictory nature" of the social control exercised by sexual science (1988:14). This analysis is specious given that Foucault's entire oeuvre of work painstakingly details the ongoing production of power through constellation-like dimensions of discursive production (Foucault 1978; Weeks 1991:162-166; Foucault, Martin, et al 1988:126-131). Discourse may censor, but only with the aim of producing other refined techniques for inquiring about sex-this is the open secret of sexuality in Western thought. Sexual discourse is not repressive, it is productive. 
Sexuality provided class-based intellectual weaponry to enforce certain relations between social members for the benefit of ruling classes. Sexologists constructed sexual subjectivity with economic subjectivity to help reconcile "the contradictory structure of an ideology simultaneously embodying both productivist and consumerist values"

(Birken 1988:40). In other words, sexuality covers contradictory evidence emerging from a materially changing society. Cultural bodies, pleasures, and affections also expressed these changes in dynamic sexual cultures. Sexologists understood sexuality to naturally order energy, needs, and impulses. This was considered normal for male, heterosexual, rational patriarchs, but intensely problematic for everyone else.

Sexologist Havelock Ellis imagined sexual impulses moving along three trajectories, "the immediate discharge of masturbation...discharge of so-called perversion ... and the long delayed discharge he believed inherent in normal or heterogenital love" (Birken 1988:42). This gave a new meaning to "waiting until marriage." A metaphor of hydraulic desire dominated his account of sexuality. Masturbation is not ideal, so if consumption is not realized then symptoms of perverse sexuality emerge. A symptomatic sexuality is anything other than a normal mapping of economic masculinity. Theories of perverse and deviant pleasure were assumed by sexologists to carry natural frustrations emerging from a scarcity of desirable objects to consume. Deviant affections are cases of falling marginal satisfaction. Deviant pleasures are signs of failed utility and indicative of failed economic consumption by irrational men. Sexologists navigated between addressing the natural order of perverse sexualities, while offering some promise of rehabilitation based on accounts of neoclassical economic subjectivity. This is the sexological prescription we maintain as sexuality. 
Krafft-Ebing's (1965 [1894]) composite of sexual desire proposed a potentially dangerous quantity of desire, which no less than all of civilization must work to contain. Subsequently, what sexological discourse offered the sexual deviant were theoretical prescriptions and cures only through other fulfilled desires, or the slight possibility that cravings would eventually erode, or hopefully get explained by a future theory of natural bodily defects (Dean 1996:20). So, once the deviant was ensnared either by police, the concerned husband, the psychologist, the reformer, or the moral vice squad, there was no way out of the sexological system of sexuality.

Bloch's (1936[1909]) other opus Sexual Life of Our Time: In Its Relations to Modern Civilization also sets out on the bourgeois adventure of making universal and natural meaning out of cases of sexual perversions. He offered neoclassical economic therapy as bodily cure. Bloch valiantly attempted, through twisted logic, to salvage masturbation as natural until it was morbidly expressed by "individuals who are previously morbid" (1936:411). Similar to sexology's general inability to "locate the sexual definitively in the body" (Dean 1996:21), Bloch struggled to make the case that sexual perversions, gender differences, prostitution, and enjoyment of pornography are definitive bodily disorders. He instead employed sexuality as an obvious backdrop and self-evident justification for these moral perversions. In any case, his estimation of himself and his class is evident in the following warning about pornography and erotica:

These obscene writings may be compared with natural poisons, which also must be carefully studied, but which can be entrusted only to those who are fully acquainted with their dangerous effects, who know how to control and counteract these effects, and who regard them as an object of natural research by means of 
which they will be enabled to obtain an understanding of other phenomena. [Bloch 1936:734]

The right men with the right mind do not need to protect themselves, they just need to know they can.

In this chapter, I explained how sexological discourse constructed sexuality in parallel to economic philosophy. Like neoclassical economic philosophy, sexologists appealed to a theory of desire that mirrored economic man and employed similar ideals, like a marginal utility of desire and consumption. Sexologists composed human sexual subjectivity as distinctly rational, male, self-centered, and upper-class. Sexuality also served to increase the construction and categorization of perversions. Sexologists also elaborated theories of sexuality that aimed to explain and possibly rehabilitate deviants it perceived in the newly modernized world. An outlet for normal desire must be found, hopefully in the (normal) coitus of heterosexual expression, but the outlook is never good. Perhaps in frustration, sexologists" "concern with deviance grew more obsessive" (Dean 1996:8) and necessitated a psychological explanation:

This shift in focus away from sexual practices to the psychology of perversions was consistent with a general transfer of interest from the consequences of acts to their causes, from the description of behavior to a preoccupation with the impulses that drive it. [Dean 1996:19]

Sexological theory paralleled and always depended on neoclassical notions of economic man and his supposed desires; there is a necessity in realizing sexual pleasure, but only in a rational, male, economizing way. I argue that sexologists retained this human economic 
subjectivity by placing rational, self-interested, upper-class male consumers at the center of a supposedly universal human sexual subjectivity. They named this sexuality.

Finally, I attempted to demonstrate that class-based anxieties and class struggle motivated sexological research and facilitated the construction and idealization of sexuality. In another case of frustrated utility, late- $19^{\text {th }}$ century and early- $20^{\text {th }}$ century sexologists are never able to contain or rehabilitate what they document (either through documentation, or later, therapeutic psychology). Sexologists attempt, and fail, to render deviant bodies and desires theoretically stable, ahistorical, and universal as much as economists failed to capture all the material realities and account for the fluctuations in the political economy. Yet, sexology magnificently succeeded in establishing and concretizing an immaterial and supposedly non-economic ideal of sexuality as a natural expression of all humanity. 


\section{Chapter 3: Queering Anthropology}

\section{Introduction}

In this chapter I examine how cultural anthropologists and queer theorists contest sexual identity, sexual orientation, and sexuality as a universal, natural, and non-material frame for understanding bodies, pleasure, affection, and agency. I will demonstrate, however, that sexuality remains a problematic analytical category for queer anthropological research. The use of sexuality to address, explain, or frame knowledge is limiting and certainly, as I will show in this chapter, unnecessary.

As I noted in the Introduction, Rogers Brubaker and Frederick Cooper (2000) exhort social and cultural scholars to pay close attention to distinctions between "categories of practice" and "categories of analysis." Social actors and social organizations use categories of practice to make sense of everyday situations and create cohesive meaning and understanding in social relations. This does not necessitate use of the same categories for social analysis (2000:5-6). The distinction between categories is instrumental in helping me understand why cultural theorists and queer anthropologists need to employ sexuality to engage with their informants through categories of practice.

For instance, research informants will use the category of sexuality (and sexual identities like gay, lesbian, straight, and other locally related terms) to explain and describe their beliefs and experiences (Bérubé 1990; Boellstorff 2005; Lewin 1993; Newton 1979; Weston 1991), and researchers will use these accounts to develop histories and ethnographies of cultural practice (Cameron and Kulick 2003; Escoffier 1998; Duberman et al 1989; Faderman 1991; Gallo 2006; Herdt 1992; Johnson 2004; Katz 1976; Newton 
1993). Following Brubaker and Cooper (2000), this does not necessitate the use of sexuality as a category of analysis. In establishing sexuality as neoclassical economic philosophy of the body, I hope this further stresses the need to reconsider the continual deployment of sexuality in queer anthropological work. I believe my argument can and should problematize the use among other disciplinary analyses of sexuality (Carver and Mottier 1998; Jónasdóttier et al 2011; Kimmel and Plante 2004; Oleksy 2009; Sinfield 2004; Williams 2006). I find the continual use of sexuality to be especially troubling, though, within the union of anthropological and queer theory.

I refer to the union of anthropological and queer theory as "queer anthropology." This union is considered relatively recent in academic institutions, but as Gayle Rubin notes this is more a product of amnesia about "Queer Studies's past [sic]" than a new disciplinary crossing (2011:354-355). A foreshadow of an explicitly queer theory in cultural anthropology is not widely acknowledged until Kath Weston's (1993) article "Lesbian/Gay Studies in the House of Anthropology." This is followed more than a decade later by Tom Boellstorff's (2007b) "Queer Studies in the House of Anthropology." In this chapter, I will accentuate how both social and cultural anthropologists and queer theorists confronted similar, significant intellectual dilemmas prior to the official recognition of queer anthropology (at least by academic theorists and academic institutions). I then briefly review three criticisms of cultural anthropological knowledge and then introduce materialist criticism of queer theory. I compare how cultural anthropologists and queer theorists attempt to account for human subjectivity within social constructions (like "sexuality") and still make sense of human social 
agency, resistance to domination of life-ways filled with affective alliances and bodily pleasures.

Simply, how are human sexual subjects understood as cultural compositions and also as vibrant confirmations of social savvy and social resistance? This is no simple task; I attend to this dilemma and am prompted to employ "new" theories of queer anthropological sexual subjectivity for this work. This dilemma is explicit in queer theory: how can we study social construction and simultaneously assess social and political agency (Jagose 1996; Wilchins 2004)? Queer theories propose self-conscious attempts to change thinking about social life and encourage resistance to forms of sexual and gender injustice. I address this pursuit of a holistic sexual subjectivity mapped above social and historical specificity as a fertile "queer dilemma."

I celebrate the achievements of queer anthropology (so far) but remain deeply troubled by an overall reliance on sexuality to frame both ends of this dilemma. Queer anthropologists assemble theories carefully, and even lovingly, in an attempt to understand pleasure and agency in material, political, and lived ways. The effort considers ways to also comprehend, then contest, the discourses of Western sexuality as necessarily universal and meaningful for all humans everywhere — at all times. In doing so, queer theorists and cultural anthropologists attempt to contest the supposed psychological, universal sexual subject. In short, how do humans embody culture and also generate cultural change? There is a call for "queer ethic" in sexual cultural study that can also compose a practical ground for queer theoretical knowledge (Warner 1999, 2012; Crosby, Duggan, and Ferguson et al 2012; Tapley 2012). I believe cultural ethnography can answer this call if it attends more closely to it analytical assumptions 
when deploying sexuality. In this way, I hope to expand on what Eve Kosofsky Sedgwick offered when thinking — queerly — of other theoretical possibilities for social and cultural research and political economic criticism:

That's one of the things that "queer" can refer to: the open mesh of possibilities, gaps, overlaps, dissonances and resonances, lapses and excesses of meaning when the constituent elements of anyone's gender, of anyone's sexuality aren't made (or can't be made) to signify monolithically. The experimental linguistic, epistemological, representational, political adventures attaching to the very many of us who may at times be moved to describe ourselves as (among many other possibilities) pushy femmes, radical faeries, fantasists, drags, clones, leatherfolk, ladies in tuxedos, feminist women or feminist men, masturbators, bulldaggers, divas, Snap! queens, butch bottoms, storytellers, transsexuals, aunties, wannabes, lesbian-identified men or lesbians who sleep with men, or...people able to relish, learn from, or identify with such. [Sedgwick 1993:8]

This queer mesh of possibility supports experimental and counterintuitive ways of thinking about human sexual subjectivity. This offers a creatively porous backdrop from which to criticize and think about sexuality.

Lastly, in this chapter, I examine recent developments in queer anthropology. I argue that despite brilliant contestations of sexuality, explicit maintenance of sexuality as a category of analysis constrains anthropological and queer holistic visions of sex as material and agentive (and culturally and locally specific). A more complete deconstruction of sexuality is necessary even here-a critical analysis that should emphasize sexuality as a limiting framework for interpreting and explaining material bodies and pleasures. This limitation hinders more radical political thinking about pleasure, agency, and material life. 
I then note a final queer dilemma: does dismissing neoclassical-inspired human rationality produce an insurmountable obstacle to theorizing human pleasure-oriented subjectivity? Namely, does criticizing a rational economic human subjectivity block possibilities for theorizing sexual subjectivity as social agency? If we hope to address human subjects as rational, material, sexual subjects are we limited in our effort, from the start, by an over-reliance on criticisms of economic rationality? I explore this final queer dilemma, before addressing Out in Theory: The Emergence of Gay and Lesbian Anthropology (Leap and Lewin 2002) and concluding this thesis.

\section{Anthropological Queerness}

The subject of anthropology is the human, and the human is a cultural being. The anthropological human subject embodies both culture and cultural change. Determining what "culture" is, does, and can be ultimately traces dense and arguable boundaries between empirical science, history, and political theory. Anthropological culture is conceived as human social behavior: a complex whole of belief and practice. Kate Crehan assesses that cultures "are in some sense patterned wholes... fundamental to the anthropological notion of culture as a 'way of life', however that may have been understood" (2002:42). Culture is understood in diverse ways. Raymond Williams (1976) noted culture as a most beguiling term in Keywords: A Vocabulary of Culture and Society. Despite this range, anthropological culture is generally understood as patterned systems of meaning, neither entirely bound nor entirely subsumed within larger power contexts (Crehan 2002:42-45). In this milieu, cultural anthropological concern is knowledge of the cultural "Other." Yet, as cultural anthropologists manage this complex 
whole, they too have moved to more applicable terms like identity and discourse (Foucault 1978), and habitus and doxa (Bourdieu 1977).

The cultural anthropologist assesses human subjectivity within culture and then attempts to portrait a specified cultural subjectivity within an understanding that all human subjectivity is cultural. The cultural anthropological project manifests by considering the human subject as part of culture, but who also lives and acts as a knowledgeable cultural agent. The anthropologist must, therefore, also rely on subjective common sense, reflective accounts, and memories of the cultural subject's own telling. In turn, ethnographic data is gathered and interpreted by the cultural anthropologist. Ethnographic knowledge endures then as inter-subjective accounts of humans in culture and human culture more broadly. Knowledge is constructed subjectively through the anthropologist's own cultural beliefs. Though this perspective may not circulate among today's cultural anthropologists in the same ways, it still deeply resonates with the queer dilemmas I propose in this thesis. Historian George Stocking (1989) proposes this anthropological longing for culture as a desire to capture what it means to be a cultural human being, and a longing to somehow limit one's personal peculiarities and passions when interpreting 'Other' cultures. This is a generous and noble interpretation of cultural knowledge makers as human ambassadors to other humans for other humans. Though some may criticize this vision as politically naïve, I am still inspired by this historical interpretation of desire and longing for a wider cultural understanding.

The quality of anthropology's effort and its status as a human and social science are not immune to broad critiques and anxieties. I now address three major criticisms of social and cultural anthropology. I roughly sketch this in historical order but ultimately 
recognize these criticisms neither begin, nor end, within the intellectual work of social and cultural anthropology. I offer these criticisms because I find useful parallels to the queer theoretical project. I begin with the assessment of the "problem of culture." Next, I briefly address the historical traditions of race, primitivism, and human difference within social and cultural anthropology. Finally, I examine postcolonial and postmodern criticism as aimed at anthropological knowledge and anthropologists. I suggest these criticisms create a fertile ground where queer anthropology blooms in the intellectual aftermath.

As Michael Elliot explains in The Culture Concept: Writing and Difference in the Age of Realism (2002), the problem in the beginning of anthropology was "to portray culture as a coherent object without ignoring the possibility of cultural change, and to appreciate the complexity and power of culture while still accounting for the fate of the individual at odds with it" (177-178). At the turn of the American and European $20^{\text {th }}$ century the concept of cultures made two other irreconcilable fears logical: the fear of homogenization by the "leveling forces" of technological modernity, and a fear of miscegenation and other racialized collusion (Elliott 2002: xv). The historical concept of cultures was also a means of alleviating social anxieties through the systematic reduction of "other" culture into something fully separate in both space and time-an effort to produce subjectivities of difference divisible by geographic space and evolutionary time. This type of cultural analysis produced so-called primitive cultures and peoples. This sentiment seems to still hold sway in contemporary thinking on anthropology. I think of the recent addition of the Anthropologie store in gentrified spaces. It is a high-priced 
trinket, household goods, and clothing store that appeals to a notion of arts and crafts produced by fleshless and spaceless global "cultures."

My peers often commented on their slight embarrassment in revealing their anthropological studies to other students because notions of "primitive people" in contemporary times still circulate. It was also due to few peers grasping what anthropologists study (apes? sex? "Indians"? bones?). This reticence also functioned to avoid titillating and short-sighted comments anthropology sometimes inspired in others. Anthropology's diverse scope across four general sub-fields of knowledge (social and cultural anthropology, archaeology, linguistic anthropology, and biological anthropology) certainly inspires cross-disciplinary confusion.

My peers and I would laugh when we assessed the diverse texts we would tote, from evolutionary studies on human ancestry to ethnographies of romance and kinship. Our humor aside, this reveals our own confusion over how to embrace a proper disciplinary history in a climate of political suspicion about cultural difference. Yet we also understood through our studies that now taken for granted assumptions of cultural subjectivity, cultural relativism, and beliefs all humanity's equivalence is also rooted in this disciplinary history. As Regina Darnell points out, notions of human equality were not always granted the almost unconscious status in Western political life as they are today (2001:12-28). Of course, these sentiments are not shared by everyone. Primarily, though, cultural anthropology is criticized for its role in the historical shaping of nonWestern "primitivism". Despite the historical condition of this charge, anthropologists still deal with similar short-sighted criticism. Regina Darnell and Stephen O. Murray 
(2001) argue that grappling with these invisible genealogies should continually invigorate our research. They state:

Much in our disciplinary past does not meet present-day standards of ethics, indeed, is ethnocentric at best. But while other social scientists continue to emphasize the gap between civilized and so-called primitive - a perspective deeply embedded in Western civilization - anthropologists have been listening to cultural others and trying to engage in dialogue. There are lessons in the failures as well as in the successes. [Darnell 2001: xiii]

Failures and successes need not remain invisible, each are worthy of historical and contemporary discernment. And the effort to actually engage with real, material human beings I consider a necessary endeavor, perhaps even more necessary in our time.

Recent efforts in queer theory similarly attempt to celebrate the accidents, failure, and missed connections in cultural life - to seek out invisible genealogies that others shy away from in embarrassment, in shame, and with melancholy political apologies (Halberstam 2011). Yes, anthropological understanding coordinates a complicated set of contemporary politics, historical embarrassments, and cultural misunderstandings. The anthropological tradition and its methods remain, however, a unique project precisely because it risks confronting the object of inquiry—cultural subjects are worth knowing, "people are not dupes but experts, analysts, even theoreticians" (Darnell 2001:7). This effort is valuable because it attempts to synchronize ideas about power/knowledge, complex sets of cultural crossings, and always pungent political choices.

There is another shared anthropological and queer dilemma about human subjectivity: what does it mean to be different? What does it mean to be different across 
borders and within liminal spaces? Postcolonial criticism launched in the 1970's to the 1990's implicated anthropological traditions within colonial practices of domination, and contested idealizations of cultural difference (Huggan 2001; Said 1978). Postcolonial theorizing criticized the concept of culture, and it attempted to illuminate the complexity embedded within the meaning of nation, Empire, and the citizen. This criticism also reminded scholars that knowledge makers should be held accountable for the fates of those being studied (Argyrou 2002). This criticism revealed how material life was always battered by the flows of colonialism and postcolonial globalization. There are no cultural islands in postcolonial theory; cultural subjectivity is political subjectivity. This idea is also intensely cultivated in queer theories - there are no non-queer islands of apolitical sexual subjectivity. But does this mean researchers will always locate politicized sexual identities everywhere?

Postcolonial theorist Chandra Mohanty (1995) criticized liberal, Western feminism for reproducing colonial relations of gender and sex within global feminism and empowerment programs. Western feminisms may work under the banner of liberation but don metaphorical masks of culturally universal womanhood—an assemblage of Western political detail, accented with ethnographic detail for intellectual concealment. With this postcolonial perspective in mind, social and cultural theorists should be measured as knowledge gatherers and fact-makers on race, native peoples, Westward expansion, and often in service of Imperial and colonizing efforts (Patterson 2001:3; Biolsi and Zimmerman 1997). Postcolonial critique should still help serve as a warning when social and cultural theorists are now expected to cultivate knowledge and 
comment on the diversity of global "sexuality." The demand for a universal sexuality is a perilous queer dilemma.

Similar to Mohanty's criticism of a recognizable, straightforward, universal womanhood, we now seem to expect a universal sexuality waiting to be freed. There is now a demand for an intelligible, universal sexuality. This demand is especially prevalent in ideals of a "gay" subjectivity waiting to be freed throughout the world. Documentary films like Dangerous Living: Coming Out in the Developing World (Scagliotti 2005) and the PBS broadcast Frontline: The Dancing Boys of Afghanistan (Doran 2010) offer ample evidence of this effort. Both films express a passion for sexual freedom and autonomy, yet neither documentary adequately addresses local and material contingencies that profoundly complicate Western efforts to raise a banner for universalized sexual freedom. For example, in Dangerous the "developing world" is never addressed as a postcolonial effect. Local forms of sex, pleasure, and affection are not connected in any meaningful way to global politics except to assert that "coming out" as gay is dangerous in Egypt and Iran, and viewers should unquestionably condemn regimes that condemn "homosexuality." Certainly pleasure, affective alliances, and real lives are at stake in this documentary, and it is indeed alarming to watch anyone rounded up and chained, for any reason. But this documentation is also clear evidence of a tendency to universalize sexuality as sexual identity and un-problematically equate this to political, democratic freedom that is only enjoyed in the homeland of the filmmakers.

Jasbir Puar (2010) warns of the tendency to assert Western sexual freedom as rhetorical evidence for global political and military incursions. She condemns the neoliberal equation asserting American and Western tolerance of "homosexuality" as 
evidence of democratic equality. She names this a "homonationalism" that works to codify anti-Muslim extremism, racism, and ethnocentrism within ideals of sexual freedom. As I consider the actual political ambivalence and resistance to sexual differences in Western nations (Rubin 1984), I understand this with some irony.

In Dancing Boys, documentarians propose themselves as offering anthropological insight into local traditions of dancing boys. The rituals and performances of the dancing boys (some adolescents, but mostly teenagers) are scrutinized by the filmmakers and condemned as practices of sexual predation. The dancing boys are often "purchased" through family networks, or traded, and perform stylized dances for rural men's associations. It seems that some of the boys are highly valued, some are physically harmed, and some engage in sexual exchanges with certain men. There are a number of ways to criticize cultural practices in various locales, and one should never discount the need for political intervention in practices of abuse and torture. But my criticism asks how this long-standing tradition (the filmmaker makes this point) is presented as obvious evidence for Western intervention in "tribal" areas of Afghanistan. The film's narrator admits that a dancing boy is an "ancient" tribal practice yet "secretly revived." Apparently if it was ancient, but never ceased, it would be less of a concern. Either way, the history, anthropology, and variable details of this tradition are not presented, but the need for sexual "modernity" is ostensibly a rationale for military and political intervention of some kind.

The third criticism of anthropological knowledge is postmodern. Postmodernist stances are used to critique the ideal of an apolitical, knowable, and universal human subject (Connor 1997; Lyotard 1984; Rabinow 2003). Postmodernism intentionally 
ruptured the possibility of an apolitical cultural reality. In other words, how do we assess whole human subject in the first place? What potential knowledge is eliminated by ideals of normalcy? Accordingly, erecting "legitimate" knowledge is always at the expense of other ways of knowing. Effort should be made to determine what systematization buries, not what it supposedly reveals (Rabinow 1985). Yet we humans must live and cooperate within some set consistencies; human culture is defined by this fact. How do we preserve values of equality within this contested theoretical postmodern terrain? This positions and substantiates some queer theorizing as well. The system of sexuality can be thus examined, queerly, for what it disguises in the service of a coherent systemization for the body and its pleasures — called sexuality. Yet how do we move from one set of cultural coordinates (and cultural places) to another and still preserve any idea of equality and nondiscrimination that may have been courageously carved from a sex/gender system of sexuality?

With these previous examples I illustrate how historical, postcolonial, and postmodern contentions cut ragged paths within academic disciplines, and distinctly alter cultural research. I hope reviewing these criticisms foregrounds a key (and queer) question: Whose thinking is privileged in the politically and materially loaded circulation of meaning? Simply, this reminds me of what children hurl back when called upon to change their behavior or perform some tedious task: Who says? With these serious criticisms one could assume cultural anthropological theorizing would collapse under the weight of the charges (certainly some wish this), but it changed, adapted, and I argue improved. Many of these indictments aimed beyond anthropology to Western philosophy, and epistemology more generally in the first place. The absorption of these criticisms, 
though, sets a particularly appropriate stage for queer theorists' direct, politicized, and critical work in destabilizing normative knowledge about sex and sexuality within cultural theory. Perhaps it is no surprise then that queer anthropology has formed such a productive embrace in the last decade (Boellstorff 2007b; Bousiou 2008; Gopinath 2005; Gray 2009).

\section{Thinking Queer Anthropologically}

The Queer Nation Manifesto, distributed during a 1991 protest in Washington D.C., partly states:

It's not about the mainstream, profit-margins, patriotism, patriarchy or being assimilated. It's not about executive directors, privilege and elitism. It's about being on the margins, defining ourselves; it's about gender-fuck and secrets, what's beneath the belt and deep inside the heart; it's about the night. Being queer is "grass roots" because we know that everyone of us, every body, every cunt, every heart and ass and dick is a world of pleasure waiting to be explored. Every one of us is a world of infinite possibility. We must fight for ourselves (no else is going to do it) and if in that process we bring greater freedom to the world at large then great.

The intersection of queer and anthropology may surprise some scholars and activists; what with anthropology's emphasis on extant culture and queer theory's initial focus on textual criticism aimed at Western society's heteronormative (the assumption that heterosexuality is always natural and normal) and homophobic social institutions. I hope by reviewing the aforementioned criticisms the crossing of anthropology and queer theory is clearer. 
Queer theorizing proposes intentional, politicized ways to disrupt binary thinking about the sexed body, gender, and especially sexuality (Jagose 1996; Wilchins 2004; Warner 1999). Queer theory crucially re-imagines subjectivity and the categories of sex, pleasure, and agency in relation to sexuality (Turner 2000:106-138; Butler 1990; Sedgwick 1990). Heteronormative assumptions continually assert heterosexuality as natural, essential, biological, and normal for all people, everywhere. Heteronormativity is critiqued by queer theorists as male-centered, genital centered (the act of "penetration"), and intentionally ignorant of political and material economies of sexual culture. Heteronormativity undergirds and constructs much of contemporary and conventional thinking about sex, identity, and desire; this presupposed logic commands allegiance in deep and wide-ranging ways (Jagose 1996; Wilchins 2004).

Queer theorists attempt to critique "normal" heterosexuality because it remains the touchstone for the majority of contemporary social institutions (family, education, politics, religion, government, among many others). Queering heteronormative life proposes self-consciously transgressive confrontations with the normative rules and expectations of sexuality (Turner 2000:1-35; Sullivan 2003:37-56). Queer theorists attack the coherency of identity, and they condemn registers of sexual identity as absolutely necessary in contemporary social life. Queer theorists are more interested in what people "really do" and, critically, what they do in resistance to domination and injustice.

Queer theorizing then proposes necessary political and social breaches (Jagose 1996; Wilchins 2004; Warner 1999; Sullivan 2003) in the damming and containing of gender, sex, sexuality, and even love (Kipnis 2003). Through close inspection artificial reservoirs of assumed natural orders can be disrupted. Ideally, sexuality is disrupted as an 
apparent, universal category of meaning and a binary notion of sexuality, understood as heterosexuality or homosexuality, is rejected (Foucault 1978; Halperin 1990). Queering, perhaps of all sexual theorization, recognizes how sexuality operates as a discursive regime in contemporary Western culture. It takes Foucault's work on sexuality as central to its project (Spargo 1999). In other words, queer theorists assert that sexuality is the way we, as cultural and sexual subjects, are allowed to understand sexual knowledge about ourselves, about others, and about what human bodies potentially can be. Queer theory violates paradigmatic thought on sexuality's supposed essential humanness.

Despite all of the contemporary research on "sexuality," an ideal of essentialist thinking on sexuality still remains hegemonic in Western culture (Vance 2005:15-32). Sexuality is now an important topic of research in the majority of academic disciplines. It is called trendy, celebratory, justified, and necessary; it captivates contemporary social theorists and social scientists. Thus in name and in study (even when contested) sexuality remains the premier way for thinking about pleasure, affection, intimacy, and social agency. It is a supposed bodily container that holds multiple, contrasting ideations of the body and its pleasures, but still manages to contain them all. Sexuality circulates in pragmatic, every day, sophisticated, and politicized ways. To queer theorize is to begin with the assumption that sexuality is a historical and not altogether pleasant frame for understanding bodies and pleasure. It is assumed to be for our bodies - for all bodies, in all places, and all times. In its monolithic place, queer theory offers instead theories of fluid desires, contingent pleasures, and overlapping affections and intimacies.

In summary, queer theorizing rejects a stable, natural essence to sexuality as bodily pleasure and affection. It also equally rejects positing that "truth will allow us to 
recognize without shame the meaning of our desire" (Mansfield 2000:105). Queering aims to tear apart, to render unstable, to expose bias, to offer critical questions, but no set answers, to upset, to delegitimize, and to "camp up" (Newton 1979) heteronormative knowledge and all its institutions. Queer theorists like Riki Wilchins, Michael Warner, Kate Bornstein, Jonathan Ned Katz, Eve Kosofsky Sedgwick, and Jeffrey Weeks criticize assimilation and instead value radical political interrogation and action (Jagose 1996; Weeks 1995; Sullivan 2003).

Though queer theorists' political practices may not neatly align, questions about the value of assimilation remain a central node in queer criticism. In this way, queering celebrates the individualized and radical potential for altering social meaning. This dovetails with the anthropological need to account for social agency, resistance, and cultural change. To queer is to realize both the realities and possibilities that attend to fluid expressions of pleasure, affection, and intimacy. I argue this composition of human sexual subjectivity remains cultural, but queer theorists also stridently value the wielding of cultural practices in socially disruptive ways. Queer anthropologists then must invest human subjectivity with abilities that counter hegemonic order in clever, social, and personal ways. The queer anthropological subject is composed as simultaneously valuing disrupting approved sexual and bodily behavior, and granting pleasure to behaviors deemed illegitimately sexual.

Despite this ambitious focus on agency, queer theorists are routinely criticized for feeble work on material and pragmatic daily existences where agency actually takes shape in everyday and sometimes not so fantastical ways (Hennessy 1996, 2000; Morton 1996:1-33). Queer theorists are criticized for avoiding key material determinants like 
class, race, reproduction, and other aspects of life. Rosemary Hennessy outlines how identity political agendas, whether queer or not, set out to legitimize oppressed social groups while "leaving the organization of social life in fundamental ways unquestioned" (1996:215). This is evident in an anemic, if not wholly absent, critique of late-industrial capitalism. Critics argue that instead of offering economic solidarity across classes, queer theories actually do little to disrupt hegemonic culture and merely enable illusions of critique by lauding "porous, gender-flexible and playful subjects, subject more adequate to the multinational commodity exchange" and this is "embarrassingly inadequate" (1996:232).

I ask: Does queer theory merely replicate the normative customs it hopes to upend, queer, and make strange? Dana Cloud certainly assesses queer theory in such a way:

In spite of its manifest opposition to normalizing familial discourses, [queer] replicates this logic...Further, queer theory, like family values rhetoric, discredits collective political responses to social problems in favor of ludic textualist strategies. It poses utopian experiments in intimate fulfillment—akin to the $1950 \mathrm{~s}$ suburban family ideal — in lieu of a collective, political struggle. [Cloud 2002:72]

In this estimation queer theory ineffectually theorizes intimate, sexual spheres as sites of resistance and emancipation. In other words, queer theorists simply imagine our affectionate alliances and pleasurable capacities hold all the seeds for social transformation and economic equity. For critics like Cloud and Hennessy, structural economic problems are cast onto so-called personal lives as personal problems (something neoliberalism already does); queer theory may simply sustain inequitable 
economic structures. Is effective political attention deflected away from politics when theorists are mostly concerned with self-inventions of identity, and imagined arenas of private life? I propose that queer anthropology offers a tonic to such sexual and material concerns directed at more theoretical queer studies. Queer anthropologists Tom Boellstorff, Martin Manalansan, David Valentine, and Kath Weston must manage both queer theoretical ambitions and anthropologically grounded realities of human cultural subjectivity.

Sexuality does remain an evocative theory of individuated personhood, heteronormativity, and masculine economic rationality despite queer efforts to historicize and destabilize these embedded meanings. Yet, our queer anthropological efforts can also aim through sexuality to disrupt what Hennessy argues is "capitalism's increasing colonization of the body and sensation" (Hennessy 2006:388). She further notes how "Affective needs that are organized into what gets called 'sexuality' are only one aspect of much broader affective and sensate relations that feature in everyday life" (2006:389). This is a vital point and queer anthropology may offer this queering of structure and of everyday life—-but I argue this potential is corroded when employing and relying on sexuality to describe and explain pleasure, affection, intimacy, and social agency.

\section{Sex, Sexuality, and Economic Development Programs}

I use critical discourse analysis to challenge the paradigmatic status of sexuality for framing and discussing pleasure, affection, intimacy and social agency throughout this thesis. The ideal of a coherent and universal sexuality simultaneously maintains understanding of other bodily domains like health, reproduction, gender, as well as other 
embedded meanings of sexual identity, sexual politics, and familial life. A queer dilemma is thus invoked in economic development programs that focus on sex and sexuality: how is sexuality in these cases an assumed a priori universal category, yet also a domain for self-inspection and active social interrogation, and also a discursive site for economic promises of development? In other words, how is sexuality assumed to be something one is "born with" but also a site for understanding human subjects as dynamic, affectionate, and active social agents within economic development ideologies?

Adams and Pigg ask in their anthropological critique of economic development, Sex in Development: Science, Sexuality, and Morality in Global Perspective, "how the proliferation of modes of speaking and writing about sexuality were and are imbricated in managing complex differentials of power and in effecting dispersed means of social control, particularly through forms of self-revelation and monitoring” (2005:5). Accordingly, a key dilemma for queer anthropological study is how we can assess sexual cultures and cultural differences while managing the Western ideology of sexuality as the transit point of intelligible knowledge and meaning about sexual behavior. All the while researchers must remain nimble and imaginative enough to account for the cultural specificity of sexual cultures and resulting sexual subjectivities.

How then can we discuss sexuality — without sexuality? This is a profoundly important question to ask about economic development ideologies that promise economic incentives and benefits for participating. This is a very queer dilemma, indeed, when local informants also must manage the local ideals of pleasure and affection, in contrast to local, national, or global forms wedded in economic development programs. In economic development the category of practice bumps headfirst into the category of 
analysis. In other words, the first question for queer anthropology is how to name sex, pleasure, and affection, if not sexuality? What if the subjects of study do understand and negotiate the category of sexuality as well? Simply, what if human beings note that they "do have one?" Then, if we study local sexual practices do we simultaneously flatten local custom and knowledge while rendering sexuality as the rightful place holder for intelligible knowledge about the body's pleasures and affections? Then how can we assess this traction when all the choices are composed in the context of real economic need and the promise of economic development? These questions foreground the call for a queerer anthropological understanding of sexual behavior, pleasure, and agency — by limiting sexuality and offering something meaningful and imaginative in its place. This all then must be translated for an audience. This is not a simple task.

Adams and Pigg (2005) pay close attention to how economic development models increasingly favor standards of sex and fertility, and recently offer attention to the ideal of identity-based, universalized sexualities. Sexuality, as a category of assumed personhood and personal understanding, supports notions of economic development in several ways. It is useful to remember that "a more nuanced and historicized understanding begins from the... proposition that a world economy is a bounded social totality which may or may not be world-wide in scope. Here, globalization refers to the reach of particular social practices throughout an extant world economy" (Germain 2000:73). This particular ideal of sexuality functioning only as a Western invention of control may ignore how systems of social production always were and continually are interconnected throughout global economies. 
Ann Stoler explores (1995) such colonial interactions with Western categorical inventions of sex and body. She argues that sexual and gendered categories are mapped primarily through colonial interactions and imperial anxieties. Sexuality, in this view, was already composed within the intimate associations of colonialism, race, and the development of education and psychology. While the factory system and industrialization develops in Europe and, later, in the United States, the colonial process is already well underway. The development of education models, psychological discourse and, essential to my study, economical sexology is inculcated and constructed with this colonial knowledge. A system of sexual disenfranchisement, ordering of slave and underpaid labor, and social anxieties about the family and women are all transformations that cannot be understood without attending to colonialism and colonial history (Stoler 1995, 2002; Minitz 1985). This history resonates in economic development programs that attend to sex, sexuality, and sexual rights in contemporary societies. This still applies then to globalization and neoliberal development ideologies today.

Attention to women's bodies, sex, and sexual rights encompass a large area of governmental and non-governmental economic development programming, as well as more recent programming under the banner of Gay, Lesbian, Bisexual, Transgender (GLBT) activism and equal rights. Both label their aid within a rubric of personal and political freedom, both deploy conceptions of coherent sexualities, and both profess a self-evident need to be freed (in these cases, both economically and politically). As Foucault clarified, however, even when using the supposedly neutral category of "sex" this presupposes and imagines a world of specific, universally intelligible sexual behavior as sex acts—as “sex" and thus as sexuality (1978:155-157). 
The International Reproductive Rights Research Action Group endeavors to present the perspectives and experiences of women throughout the world and engage in localized political action. I admire their work and attention to many of the dilemmas I detail in this thesis. The researchers make explicit a reliance on the women's own words (Petchesky and Judd et al 1998). The group declares that without "voices" of women commenting on local cultural context research into reproduction, gender, labor, and sexuality will remain embedded in problematic assumptions of an assumed universal applicability. I find this point important and necessary for my study. Their research shares a commitment to the broad category of feminist intervention in public policy, while noting that what constitutes human rights is contentious in local, cultural, and national contexts.

Rosalind Petchesky outlines (1998:19-20) how what gets counted as local and useful political intervention may still be encumbered though with issues and errors of translation, a reduction of local experiences to fit Western categorical frameworks of sex, and a misuse of cultural knowledge. Collaboration with locals is always more desirable though than not. Her research attempts to expand on several cross-cultural themes: reproduction (encompassing both biological and social reproduction throughout the life cycle); rights and entitlement (human "integrity" mixed with local understanding of oppressive local conditions); "body and self;" and "accommodation and resistance." All theorists in the group are committed to "positive action" and "empowering changes in the lives of those who are both its subjects and agents" (Petchesky and Judd 1998:20). These concepts, while providing grounding, remain highly contested within the working research group. 
Importantly, Petchesky recognizes sexuality as a separate category that includes pleasure, desire, and sex and not reducible to reproduction and the birthing of children. In doing so the group recognizes that sex and sexuality should be understood distinctly from reproduction and fertility. But is that the way sex and sexuality is experienced on the ground? Petchesky notes that intellectuals and activists in the group confront unpredictable results when accounting for local agents who may not agree, nor support the programs and politics of development (even in the name of sexual freedom) (1998:20). In other words, local agents may not always subscribe to the agendas, language, or perspective of those who want to speak politically on their behalf in the name of development, queer interventions, or anthropological knowledge. The credibility of sexuality as a category of analysis is severely strained in this context. Petchesky admirably handles this dilemma and provides a compelling framework for research into the complexity of sexuality employed as a model of development. Yet, even when the Action Group focuses on the collaborative notion of shared language nowhere is sexuality understood as already distorting an understanding of the conditions the group hopes to ameliorate, namely political economic conditions and the rights and agency of women. I am not arguing that sexuality should be disassociated from sex, but that local "sex" and pleasure may not be translatable to the researchers" invocation of sexuality in the name of the women they are advocating for. Can we listen more closely? Can we also attend to pleasure and affections that speak to local, lived experiences without hauling out sexuality to coordinate every pleasurable meaning? For example, in the essay "Not Like Our Mothers," Simone Grilo Diniz, Cecilia De Mello E Souza, and Paula Portella further explain how the categorical separation of work, labor, reproduction, and 
sexuality is not always applicable to working populations they interview who view little to no distinction between the work of cleaning houses, the work of raising families, and the work of "sexual relations" (Diniz et al 1998). This point foregrounds the body as a "working instrument," whereas Western separate spheres of sexuality and labor do not account (in fact romantically refuse) this lived reality. One woman details her life of work: "I had no youth because I got married at eighteen and life became routine. Work, heat your belly at the stove and chill it at the sink. That is all you learn. Move, chicken! Shut up, boy! Today many things are changing, but for me nothing changed. It is always the same-field, home, kids, wash..." (1998:46). This points to a need to disengage sexuality in queer anthropology and for realizing that pleasure may still be an instrument of labor and work and exchange (even when invoking sex as a pleasurable act between consenting agents) and may still operate as something not pleasurable in another context. Similarly, Adriana Ortiz Ortega, Ana Amuchástegui, and Marta Rivas in "Because They Were Born From Me" (Ortega et al 1998) detail sex as a male-initiated and male-dominated domain of pleasure, as reported by Mexican female informants. The authors keenly detail how sex and sexuality is not translatable, or cross-cultural, or a discrete realm of negotiated sexual pleasures between consenting parties. This disturbs a call for global sexual rights that speaks for women, men, and others by illuminating the contradictory (and not always evident) ways sexual pleasure is considered an aspect of the self. Like a local informant reported "I think that rights must be personal and not because someone comes and tells you, 'These are you rights'; that's like he is ordering something, right? We women have to say: "This is my right and this I have to do..." (Ortega et al 1998:172). So, if we attempt to advocate for sexual rights, as sexuality, are 
we enforcing norms of sexual pleasure that are not cross-cultural, not personal, and not local? Are we, in essence, demanding a global ideal of sexual pleasure? The categories of Western life and meaning do not always neatly map in all places, and the fundamental understanding of pleasure, affection, and intimacy may not neatly map across space within Western culture or across cultures, as queer theory makes clear.

In the context of global campaigns and local agencies, when research assumes sex as an autonomous right to pleasure we may also ignore the ways local agents report sex as a burden of social labor, or of limited pleasures, or even as tangential to selfunderstanding. As Laura Ahearn makes clear in Invitations to Love: Literacy, Love Letters and Social Change in Nepal (2001) what cultural subjects say and feel may be quite different, and depending on the context, quite distinct. She notes how ideals of individualism and romantic love were established and circulated along with the ideals and programs of economic development. Do we then demand that sex always be pleasurable in the way we need it to be? In this regard, when various programs administered by the World Health Organization, the World Bank, or the International Monetary Fund and other non-governmental agencies invoke sexuality as a necessary and obvious element of human rights, they may do so in ignorance of the way pleasure is not necessarily composed of the same choices in the assumed universal market of pleasure.

In summary, Sex in Development (Adams and Pigg 2005) and Negotiating Reproductive Rights: Women's Perspectives Across Countries and Cultures (Petchesky and Judd 1998) critically inquire how sex and sexuality are introduced and employed in economic development programs. They ask how programs of development rely on the supposedly stable, scientific conceptions of sex and sexuality that, in turn, assume an 
absence of particular moralities. They argue instead that a stance on normal sexuality already assumes Western codes of sex - albeit a moral code that assumes a "healthy" sexuality as normal sexuality. Adams and Pigg foreground criticism of sexuality's supposed "naturalness," but they still unfortunately aim to produce a usable and productive conception of sexuality that will address local moralities within development programs. As the editors remind: "all sexualities are local" (Adams and Pigg 2005:5). But, as I argue, sexuality is never local but pleasures, affections, and bodies may be.

\section{Queer Anthropology, Without Sexuality}

Manolo Guzman (2006) critiques the notion that gayness, homosexuality, and same-sex desire are mutually intelligible. In Gay Hegemony/Latino Homosexualities, Guzman demonstrates that same-sex desires in the New York, Puerto-Rican diaspora navigate and negotiate around a "long duree" of gay history (2006:1). He complicates the idea that a gay subject emerges in similar ways, always in the heart of the city (2006:1). He implicates an older racial typology of "the one drop rule" to understand the emphasis in gay culture for stable sexualities (2006:91). In other words, one touch, one "sex act," one momentary or continuous pleasure is the one-drop that proves a latent, closeted homosexuality yearning to be gay. It is unfortunate that he relies so explicitly on "homosexualities," though, to arrive at his very necessary point. He must understand that this use of sexuality-based categories enforces an idealized orientation toward objectchoice and ignores its long complex history, even when pluralized to homosexualities and contrasted with gay. Nevertheless, Guzman's evaluation of the conservative tendencies of Western GLBT political programs, and the shadow it casts over those bodies not at the 
center of the assumed cosmopolitan sexual constellation are important for future queer anthropological research.

Specifically, queering GLBT political programs reveals how global political research too often simply harmonizes sexuality with a need for freedom of choice, freedom of expression, and freedom of lifeway. This ignores material dimensions of political economy, race, and class. Mainstream GLBT politics operate within a sexual schema that recognizes sexuality (as sexual identity) as necessary evidence of a universal, essential human condition. In other words, to make "sexuality" into sexual identity, and thus a human right imperative within global development and social research, GLBT organizations must accept a logic that runs counter to expressions to more material and political choices. These organizations give life to sexuality as "not a choice" within human life. Then, paradoxically, this naturalized, universal condition is primed for sexual identification and assumed waiting and ready at the core of human sexual subjectivity, if only one had more social choices. This is what queer anthropology must navigate and overcome.

Adam Kuper (2003) follows a similar essentialist dilemma when researching new claims of "indigenous rights." He notes how indigenous groups in Canada resuscitated outmoded anthropological ideas about cultural permanence and ethnic difference to establish land-rights claims in Canadian courts. This is useful to my argument because queer anthropologists must traverse similar knowledge about the social construction of sexual identities, and strategic claims that sexual identities as categories of practice are universal, natural born orientations. But we can and should also look to a more thoroughgoing ground about bodies and pleasures to build other ideas about "rights" (if 
we want to use that term, at all). For example, we can claim all bodies and pleasures hold some salience for rights discourse, or we could instead focus theoretical attention to more generalizable affections and alliances, regardless of any conception of orientation. In either case, as Kuper notes, "It is a good idea to call people by names they recognize and find acceptable. Nevertheless, discredited, old arguments may lurk behind new words" (2003:389). This queer dilemma of enjoining universal categories (say, supporting economic development rationale in the name of sexuality, or arguing for sexual rights in the name of sexuality and freedom) clash with other research that supports more queer ideas of agency, interventions in local politics, or where the idea of choice may be more politically effective. These are crucial questions that organize the edited anthology Different Rainbows (Drucker 2001) and Tropics of Desire: Interventions from Queer Latin America (Quiroga 2000).

Drucker pays particular attention to the dissonance between the "First-World" gay/lesbian identities and the same-sex cultures and identities in, what he names, the "Third-World." He notes, "men in the Third World who have sex with men, and women who have sex with women, have their own more or less distinct traditions, realities, sexualities, and identities, which neither they nor outside observers always even see as 'lesbian' or 'gay'” (2001:207). Drucker's unease, though, is not necessarily about criticizing "gay or lesbian," but to figure how we build a movement that addresses all those who are sexually oppressed. He aims to recognize the limits of social research and political movements that only articulate a limited range of sexual identities with a backdrop of relatively stable, capitalistic economies. Drucker struggles, on the other hand, to figure what terms to use to accomplish such a task. He employs the concept of 
sexual cultures, then uses same-sex identities, and then relies on sexualities. Sexuality is the least rewarding as it leaves out transgender, sex work, and sexual behavior that cannot be neatly categorized within sexual identity. Sexual cultures, at least, provide a ground for analysis. He queerly contests hegemonic sexual rights movements that only organize those willing to speak in similar terms, and in similar ways, while ignoring the political economic conditions that motivate sexual oppression in the first place. Throughout his writing I longed for him to eliminate sexuality altogether as is clashes with his quest for a sexual rights movement that pays attention to political economy. This is complicated by sexuality that I argue is already a classed and gendered economic philosophy of the body and its pleasures.

José Quiroga (2000) similarly critiques the notion of a universal set of sexual identities, with similar needs and affections and built from an ideal of sexuality. He criticizes the imperatives of contemporary sexuality: the demand for sexual identity and social sexual visibility, the notion that homosexuality can be a useful category in all places (even in the West), and the ideal that sexuality is always a struggle for an accurate self-inspection. Sexuality, too, must always be composed with an object-choice and this obviously troubles Quiroga; he explicitly avoids pronouncing sexuality throughout the text, though he lapses into a pluralized sexualities. He pointedly asks "What use is there for a queer studies that does not articulate a critique of class?" (2000:233). In this way he focuses attention on Latin American artists, writers, and activists who eschew explicit demands for self-revelatory sexuality and swap more coded political and social interventions. He argues that a demand for public articulations of sexuality serves to stabilize oppressive political regimes by speaking in similar terms and this ignores the 
varying ways people forge alliances and resistance across sexual cultures. He hopes to enjoin research and cultural criticism that "goes beyond identity" and, as I desire, beyond an ideal of sexuality. Several other researchers also attempt to negotiate this queer dilemma. I address each of these final texts with the goal of articulating new pathways for queer interventions, away from the sexuality. I then address how each miss intellectual opportunities with their use of sexuality.

Anthropologist Tom Boellstorff offers a "queer" reading and hopes to offer new theoretical possibilities for research in The Gay Archipelago: Sexuality and Nation in Indonesia (2005) and A Coincidence of Desire: Anthropology, Queer Studies, Indonesia (2007a), Martin V. Manalansan attempts similar work in Global Divas: Filipino Gay Men in the Diaspora (2003), and Elizabeth Povinelli articulates new ways of interpreting liberal and neoliberal dilemmas of belonging, intimacy, and affection in Empire of Love: Toward a Theory of Intimacy, Genealogy, and Carnality (2003).

How can queer anthropology build an account of pleasure, affection, and intimacy that accounts for the multiple and overlapping contingencies of social life? Queer anthropology attempts to account for both culture and enculturation, both the social and radical social agency. Queer anthropologists and researchers attempt to account for social constructions of sexual identity and also a personal accounting of how these constructions fail to attest to lived, material realities, pleasures, and affections. Perhaps most importantly, queer anthropologists must address social inequities and categories of normalcy with a nuanced research program that maintains radical and disruptive political criticism. The task at hand is to build an account of human sexual subjectivity that points in these queer directions-without sexuality. 
Boellstorff offers an account of gay and lesbi Indonesians. He addresses the necessity of intersectional, cultural analysis within a study of sexuality in the Indonesian archipelago (2005). Boellstorff notes that an "Indonesian" ethnography does not exist for a number of distinctive reasons: primarily the geographic reach and local knowledge of island inhabitants renders "Indonesia" a conceptual problem. Second, national citizens do not always primarily identify with the nation as a central feature of identity. Third, anthropological knowledge has not produced a text that conceives its local subjects as "Indonesian." He then offers the lesbi and gay citizen as a newly realized national subject, not reduced to the sole product of globalization and global economic development. He does so to understand how local forms of identity are intersectional and, therefore, how Indonesian lesbi and gay citizens understand themselves within local, regional, and international cultural logics. He contrasts this to cultural analyses that overemphasize powerful institutional productions, which he argues flatten accounts of individual subjectivity and erode local knowledge in service of theorizing an abstract “discourse." He offers instead an intersectional analysis that renders sexuality very well meaningless, but then he assumes that without sexuality his other exceptional points are unintelligible.

Boellstorff's ethnographic project aims to render queer anthropologically viable. He recognizes the ways sexuality, gender, and other sexed categories are impossible to negotiate as discrete, separate, local forms. While his informants do position themselves with full knowledge of global sexual identity movements (evidenced in lesbi and gay terminology), he argues that local life is not so entirely different from the gay and lesbian subject positions profoundly shaped by the psychological and sexological discourses in 
the West (2005). But in doing so he assumes a stability of sexuality and sexual identity at "home" to then complicate the notion of sexuality abroad. He also assumes that the rational, consumer-oriented, masculinist logic already embedded in Western ideals of sexuality operates much more tidily than I would argue it does.

People negotiate, resist, and transform identity “there," and here. Boellstorff creatively argues though for theorizing "queer time" by calling attention to the ways time already operates in "straight" ways (2005). For example, assessing queer time is to reimagine other ways of being in the world through emphasizing life's dis-junctures of identity. Queer timing foregrounds the ways that life does not always flow according to timely planning. Yet, straight time is never actually followed, as human subjectivity works in queer time already. Human cultural models are, of course, indispensable to human culture, but accounts of individual agency often point to slippages as well as outright resistance. That is a departure point for creating new theories of queer human subjectivity and agency. Humans are already queer, already non-conforming to an extent, one need to just look—perhaps askew—at what already is being culturally offered, performed, and resisted.

Boellstorff notes how sexuality studies often self-congratulate while recognizing the linguistic and historical constructions of sexual categories (2005). Boellstorff critiques the supposed and obvious benefit of such recognition by complicating the portrait of a "globalized" sexuality. He claims that sexuality is neither entirely a Western conception of the self, nor a reduction of local expressions of self separate from other types of belonging. In other words, an assumption continues in sexual cultural studies that local forms of sexuality are either exclusively local or entirely subsumed by 
globalized discourse of sexual identity. As Boellstorff makes explicit, cultural and social processes are never tidy, and they do not need to be.

Sexuality need not be a singular domain moving along a single axis. Boellstorff reminds readers that research should not confuse analytical and experiential categories, similar to reducing sexuality to "sexual culture" and assuming it contains a discrete, independent logic existing separate from other parts of culture (2005). Yet, as a matter of convenience, a matter of interpretation, and a matter of writing, "sexuality" still remains a primary and discretely employed term within his effort. This exemplifies both the difficulty of his work (which he clearly recognizes) and the difficulty of escaping the imprimatur where sexuality makes pleasure, affection, and the body meaningful to readers, students, politics, and activists at home. Also, queer anthropological studies may need to express sexual cultures more in terms of similitude than difference, in this way others materialist ideas about pleasure, affection, and intimacy may move to the center of our analyses. The discourse of identity, sexual rights, and other ideas of human subjectivity need not move along an axis of sexuality. It could root in pleasure, the body, and change_- perhaps both radically inclusive and cross-culturally meaningful? Boellstorff attempts a similar aim about cultural coincidences that may be productive for queer studies.

Anthropology can theorize, not just detail queer life Boellstorff claims in Coincidence of Desires: Anthropology, Queer Studies, Indonesia (2007a). In other words, Boellstorff asks how "queering" may interrupt, alter, and reconfigure cultural notions of time, belonging, and space in both theoretical and practical ways. To queer is to make strange, to make linkages, and to make the seeming coincidences of life more readily 
available to anthropological understanding. Queer theory can illuminate distinctive domains of gender, sexuality, and a "sexed body," but he troubles these distinctions and pointedly questions the anthropological utility of these formulas. In a discussion of tomboys, femmes, lesbis, and "transvestites," Boellstorff notices the intertwined knowledge that render each intelligible in their local and national (and international) contexts. In this way, Boellstorff further argues that queer should encompass an intertwined range of understanding about non-normative identities. This may further the possibilities of imagining and engaging in queer political interventions, yet to claim a category of "non-normative sexualities" limits our critique of sexuality as always, already necessary. To make linkages between the non-normative subjects he covers also assumes that each pleasurable act, bodily movement, and expression must be categorically defined as non-normative to take on queer political importance. Queering also imagines bodies, pleasures, and agency that never fall within the surveillance of cultural expressions of recognizable identity. In other words, people can kiss, hug, touch, fuck, embrace, caress, and love without coherent and stable meaning at all. It may simply be- a coincidence of bodies, pleasures, and desires.

Manalansan (2003), on the other hand, focuses on the shifting terrains of political economy, migration, and queer identity. Queer, or gay and lesbian, can be conceived as both liberation from and submission to a modernist, liberalizing world order. In this way, to claim a sexual identity, inspired by Western sexual politics, does not necessarily mean that local life and individual expression is somehow moot. Manalansan pays particular attention to the "micropolitics" of personal identity within the lives of "gay" Filipino migrants living in the diasporic communities of New York City. Manalansan sufficiently 
problematizes the conception of "Pride Without Borders" (the theme of NYC GLBTQ Pride celebration in 1996). This theme imagines an American emancipation of sexual identity extended throughout the world in a similar fashion. In this way we must contend with the idea that the "outside" world is pre-modern (primitive, yet again). Despite this criticism, Manalansan curiously posits his ethnography as a monograph to enable a "global gayness."

He declares an alliance with what he names "new queer studies," which he sees as scholars specifically concerned with the political stakes of pronouncing a vision of the "global" while recognizing that this need not reduce local agency and local understanding. He does not make room, however, for pleasures, bodies, and agency that may desire all he celebrates, yet never desire and identify with his global gayness or gayness at all. Sexuality, in his work, takes on various local forms, but is also understood to prepare us for a vision of global solidarity. I do not devalue his ethnographic project and meticulous work, but I question why his account of micropolitics does not account for the vastly different ways cultural subjects experience and seek out pleasure, and for what material purposes, if any.

It is certainly credible to research the global political projects of both his informants and his own. Yet global political projects that aim for sexual sovereignty and sexual alliances may not actually achieve the bulk of their aims if sexual is only understood through an ideal of sexuality. There are more bodies, more pleasures, and more affective alliances operating even in the lives and loves of those who claim solidarity with global gayness. I think this is necessary to note in queer research. It is not 
just what we say we do, it also what we do. Queer anthropologists can assess that in ways that queer theorists, alone, have struggled to address in material and lived ways.

Global gayness celebrates a fantasy, and it still may be a useful and necessary one. But we should avoid a fantasy based solely on a consumptive oriented world without borders, whereas borders are entirely real when one has limited means and little political viability for crossing them. Sexuality continually constructs the same economic borders around bodies and pleasures that he hopes to undermine when he critiques the economic fantasies of "gay modernity." In any case, to maintain sexuality even as a contested framework obscures some of the economic inequities he is concerned with. Sexuality does not adequately offer a vision of a sexual subject actively forming alliances, adapting to changes, and discovering new material life ways and new pleasures. Sexuality imagines desire without social agency except for the classed and gendered subject sexuality is built for (as I noted in Chapter 2). Even "global gayness" needs a more diverse and active agent than that. His use of sexuality orders an organization of class, gender, and desire that does not do justice to his own wonderful descriptions of his informants. I turn now to a recent examination of Western life, and the ways the author conceives of bodies and pleasures, without sexuality.

Elizabeth Povinelli (2006) examines liberal and neoliberal ideologies of belonging that depend on irreducible tensions in Western political economic life. She explores the way settlers (indigenous people in northern Australia, and Radical Faeries in the United States) inhabit and negotiate liberal ideals mapped for the body. Her primary objective is to understand the way intimacy and constraint are idealized and understood in different societies, yet somehow remain synchronized across liberal zones of social 
order. Povinelli explicitly (and I argue queerly) avoids reference to "identity" and to sexuality as an explicit, a priori category. She does note that "sexuality" is determined by where and when it is constructed, but in relation to ideas of intimacy and within the governing of a liberal society. She does so to encourage other, queerer ways of thinking about the "social matrix." How does identity takes shape in liberal discourses that seek to establish norms of intimacy and, thus, containment?

Povinelli seeks to explain how intimacy is animated through autological knowledge (the assumed self-making subject in liberalism) and genealogical knowledge (the constraints, regulations, and "inheritance" of our historical knowledge); this is another articulation of the queer dilemma. She offers a theory of carnality and intimacy instead of sexuality — a provocative vision of pleasure, affection, and agency, while still addressing the limitations ordered in contemporary life. In her work she recognizes the ongoing dissonance of producing thick descriptions of "thick life." She argues that life is too rich, too thick, to be represented with anemic theories of sexual or gender identity and that we need a political program where the density of "social representation is increased to meet the density of actual social worlds" (Povinelli 2006:21). To understand human subjectivity, queerly, is to understand a people within their skin, to account for feelings that emerge, merge, and conflict across the surface of lived experiences, felt by the body, and lived through the tensions, sensations, and releases of life.

In contrast, sexuality rarely offers an interpretation of carnality other than as a problem of intimacy. Sexuality is thus far too blunt a register. It is built as an ideal for a heteronormative, male, rational consumer subject. It is built out of class struggle and social anxiety, and the very same struggles that some now hope to theorize ways out of 
by deploying sexuality. But sexuality cannot capture the passions, the fluidity, the pleasures, and the thick resistances that queer anthropological theorizing hopes to imagine. Peter Hitchcock (2003) extrapolates Arjun Appuradai's notion that resistance to hegemonic and oppressive elements springs from the process of imagination. So, as much as nations are imagined, as much as sexualities are imagined, as much as the "naturalness" of specific sexual orders are imagined, so too must the possibilities of resistance be imagined.

The challenge for queer anthropological studies is to recognize the way these orders are asserted on the body. It is to also recognize the impact on the individual "being" as social agent, and then first imagine strategies for resistance (Hitchcock 2003). We must resist propositions of sexuality as indicative of modern freedom and equity. We must counter this with the knowledge that a sexualized citizenry is already framed within limited horizons of affection, intimacy, pleasure, and thus political possibility.

Admirably, Povinelli (2006) attempts a beginning at this charge, at this counter-attack (Foucault 1978:157).

Finally, and perhaps the most perplexing queer dilemma of all, how can queer anthropology imagine possibilities for pleasure, intimacy, affection, and agency when the notion of a desiring rationality is already constructed as heterosexual, masculine, and normative — as sexuality? Material evidence of rational life-making, in pleasure, intimacy, and affection is stridently denied in contemporary sexual politics. Theories of material rationality are, ironically, rejected by sexual liberationists who laud sexual difference and diversity, but only if they are able to register these differences as sexuality—only if they "are born that way." 
What can it look like, what will it feel like, what political possibilities, and what queer anthropology is possible if this queer dilemma is no longer a dilemma? What new intellectual pathways may emerge when sexuality is rejected? What new ethical pathways will emerge when queerness is embraced, not as an identity, but as a matter of contestation, fluidity, change, fairness, pleasure and each understood as potent evidence of rational thinking, ethical living, and active social agency? Queer, indeed. It is useful to remember here that the richness of anthropological knowledge is built upon the desire for holism, not on mechanical descriptions and hypotheses. Humans turn to other humans not to make sense of the natural world in atomic specificity, but to make sense of a spectacular range of emotion, expression, and cultural logic. Similarly, Gayle Rubin offers that "the complexity of cuisines is no testament to the belly's hunger" (1984). Queer anthropology may provide the possibility for exploring sex in all its contentious, problematic, sublime, pleasurable, and disagreeable bearings. These final questions provide ground for me to address Out in Theory: The Emergence of Gay and Lesbian Anthropology (Leap \& Lewin 2002).

Leap and Lewin (2002) make a claim about the necessity and validity of research on sexual cultures. They may work from a problematic assumption that anthropology formerly repressed knowledge about sexuality (Rubin 2011:354-355). Vital work that aims to restore sex to its proper place in the house of anthropology (Weston 1998) narrates an emphasis on loss, then a recovery of knowledge. This narrative manages the story of sexual knowledge too closely to an ideal of repression; Foucault noted repression was a hypothesis to produce, among other sentiments, a feeling of radicalism (Foucault 1978). The story of our "repression," ironically gives life to sexuality and restricts other 
possibilities for acknowledging bodies and pleasures. I note this to bolster my critique of Leap and Lewin's outstanding, but problematic, Out in Theory (2002).

During the last three decades a necessary and not always welcome development of gay and lesbian anthropology changed the way anthropology addressed sex, theoretically, ethnographically, and within the discipline's professional practices. Leap and Lewin certainly honor the tradition of anthropology as a necessary political orientation, as well as a necessary academic discipline. They address the anthropological crisis between the relation of anthropology and its subjects; they provide space for feminist interrogations of a pervasive androcentric bias in the discipline, and they positively evaluate the critical stances of postmodernism, postcolonial studies, and cultural studies (Leap and Lewin 2002:1-2). This supports the anthropological introduction I offer in this chapter, but from this agreement we part company. I find it instructive to paraphrase Donald Kulick's review of Leap and Lewin's earlier work Out in the Field: Reflections of Gay and Lesbian Anthropologists (1996), which Leap and Lewin criticize in the introduction of their follow-up work Out in Theory (2002). Kulick expressed concern about their specific focus on gay and lesbian professionals "coming out," and the political ramifications of pursuing gender and sexuality research. He argued this produced substantial barriers to younger anthropologists identifying and applying newer, queerer paradigms in anthropological research. Leap and Lewin defend their well-received collection in light of his charge. I find Leap and Lewin's volume to be important: it helps students and scholars understand anthropological disciplinary history and academic sexual politics. Yet Kulick's critique is well-founded, and I argue that the exclusive focus on an emergence of "gay and lesbian" 
anthropology does work to limit queer research. In response to Kulick, Leap and Lewin argue that queer connections to anthropology were and still are under-developed. They maintain that queer scholarship is notoriously anti-empirical, and that queer is an "inclusive, generic focus" and thus not helpful. Leap and Lewin also reason that when preparing their text there were absolutely no anthropologists willing to address the connection between queer theory and anthropology (Leap and Lewin 2002:10-12). With this dismissive coverage I can make one assumption as to why.

The right for scholars to identify as gendered and sexual beings certainly should not limit opportunity in the professional academy. These identifications, however, do not necessarily produce a more inclusive anthropological perspective on theory and practice, by default. Anthropologists must also consider the theoretical, practical, and ethnographic limits of this emphasis. Gay and lesbian-identified people obviously produce vital, critical work within social and cultural research. Yet limiting "queer" or any other study of pleasure, affection, and agency under a mantle of "gay and lesbian" considerably over determines the necessity of Western social and sexual categories. Sexuality, as a category, cannot be linked with the criticism I offer here if we already assume that our social systems of identification are always politically, if not anthropologically, necessary. Therefore Leap and Lewin's framing of sexual identity categories, sexuality, and sexual orientation should be considered as problematic as an androcentric bias or homophobic panic in academic life and in the production of our vital research.

I am not positing that homophobia, gender bias, and a general sex-phobia do not regulate and restrain social and cultural research. I agree they do. But anthropological analysis, queer ethnographic practice, and culture theory is not made more proper or 
more imaginative when our political beliefs, invested in sexuality, also launch our anthropological studies. The categories of gay and lesbian or straight, and categories of homosexual or heterosexual, each proceed from a belief and investment in maintaining, without question, the idea of sexuality as the premier and necessary ground from which to orient anthropological knowledge of pleasure, affection, intimacy, and social agency.

Leap and Lewin nobly argue that "coming out" de-stigmatizes anthropological research into gay and lesbian life and homosexuality and heterosexuality (1996, 2002). There is valuable work to be made by investing in studies where these categories align within identified communities and their categories of practice (as I noted earlier in this chapter). This still limits new research questions and limits knowledge on human sexual subjectivity (in any case, I am still waiting for a rich, nuanced study of upper-class, white, "heterosexuals"). In fairness, Leap and Lewin partially address this difficulty by noting that local terms for gay and lesbian practice should be included in ethnography. This though does not produce insight into the question I already problematize: how are these local terms not equivalencies, and how does this offer new ways to understand human sexual subjectivity in all its forms? Leap and Lewin imagine that without sexuality, and without gay and lesbian categories, a quagmire of descriptive relativism will ensue (2002:9). This is a necessary consideration in social and cultural research. But, I argue, that we should jump into this quagmire and reassess the historical notions that sustain "sexuality" as an immaterial frame for pleasures and affections within queer anthropology before assuming relativism will be the obvious result.

In any case, Leap and Lewin do not address how these ideals of sexuality and sexual identity occlude an understanding of overlapping "sexual worlds," which Gayle 
Rubin calls for (1984). I like this finer point, because it does not reduce everything to an estimation of "non-normative" sexual study, and this too is where queer theory often breaks down. Too often the lines of normative and non-normative categorizations resurrect sexuality without questioning it, in the first place. To queer anthropology and to anthropologize queer theory is to de-stabilize the strict limits that sexuality conjures, including the ideal of non-normative. In this way, everyone is a little bit queer, as the saying goes.

We must fully interrogate the limits sexuality engineers as a category of analysis, if not always as a category of practice. We need to reinvigorate the study of material pleasures and affections. We need to more adequately assess how normative and nonnormative, homosexual and heterosexual, and gay and lesbian all corral insights about the body and pleasure into a dull sexuality. This limits our material and political perspectives on human sexual subjectivity. We need to imagine a human sexual subjectivity motivated with agency, political intervention, belonging, and performing dynamic human affections and intimacies within and across sexual cultures.

In conclusion, Gayle Rubin notes how the use of theories of social construction "refined the theoretical bases for social approaches to sexual behavior" and inspired a "vast outpouring of work that has continuously destabilized universal sexual categories and increasingly placed sexualities in history, society, and culture" (Rubin 2002:43). So, a vibrant transformation in the intellectual knowledge of sexual categories occurred, now why not sexuality? Queer anthropology is a vehicle where vibrant transformations can continue to occur, and we can and should push further. Tobias Rees asks how to "invent new ways of being an anthropologist or ethnographer" in a world where anthropology 
can "no longer make assumptions about what is necessary for their method to produce rich ethnographic data—a temporally stable scene and subject of study" (Marcus and Rabinow et al 2008:7). It is to continually ask the question: "What is anthropology today? What could it be?" (2008:8). James D. Faubion further inquires in Designs for an Anthropology of the Contemporary (Marcus and Rabinow et al 2008):

In the aftermath of a devastating critique, identity was to organize a lot of people's projects as a kind of sun around which a variety of often quite politically inflected interests could orbit together. Multiple currents of feminism, for instance, were, in fact, quite productive in attaching themselves to the same sort of orbit. It brought in gay and lesbian studies, which seemed to me to hold the promise of being the next great force of the undoing of humanist essentialism. Unfortunately, it hasn't accomplished very much in anthropology. It is limited work, and I'm not quite certain why. [Marcus and Rabinow et al 2008:34]

Queer anthropology may answer the question by providing a necessary flexibility for this project. Queer anthropologists may also provide strategies and methods for imagining human sexual subjectivity that allows for diverse ideas of pleasures and affections, identities and non-identities, material practices and ideal relations. We must be willing to revisit and interrogate our own theoretical presumptions. In doing so, sexuality and "sexual freedom, identity, openness, and individual rights" (Engebretsen 2008:88) need not be the most commanding forces in queer anthropological studies of bodies and pleasures. We can create a queer anthropology—without sexuality. 


\section{Chapter 4: Conclusion}

The social construction of sexuality is not a novel claim (Foucault 1978). But I hoped to emphasize how the political economic background of a history of sexuality is often forgotten. Calls for economic justice, studies on the globalization of sexuality, and cross-cultural research on material sexuality are all hampered by ignoring this history of sexuality's construction. In this thesis I argued that sexuality was invented and constructed to manage social economic anxieties. This crucial point is too often understated or ignored in research that similarly attempts to understand the parallel between economic literature, sexology, and sexuality. Sexuality was developed with a

rational, male, self-interested economic subject as the normative standard from which all other affections, pleasures, and intimacies were judged.

Sexologists invented categories of non-normative affections and pleasures to assert how differences expressed by bodies and pleasures were social problems needing to be rectified. The category of sexuality was refined as a commentary on the bodies of laboring classes, migrants, and women. By critically examining how sexuality developed in parallel to neoclassical economic philosophy, which was already rooted with a classical economic male subjectivity, I hoped to show that economic ideas paralleled and aided the construction of a sexological human subjectivity. In the least, I hoped to further elaborate on the economic pedigree of sexuality. Studies that do not take this history into account often problematically assert the universality of sexuality as a meaningful category of analysis with little attention to it as an economic philosophy of the body. 
I think that employing other categories of analysis may help us imagine other ways to theorize bodies and pleasures. I hope this moves us along new research pathways. This is evident in the merging of queer theory and anthropology. I assess this merger because it is producing new research questions and new ways to address bodies, pleasures, affections, and intimacies. Anthropological research on sex already maintains a keen awareness of the culturally specific constructions of sex. Social and cultural anthropology also offers methodologies that allow us to grapple with the real, material conditions of people's lives, as they are lived. Queer theories re-frame and radicalize social knowledge of sex, gender, and politics. Queer theorists generally propose human sexual subjectivity as valiantly exceeding the limits of social control. To "queer," therefore, is to assess how human subjects engage in ongoing, active resistance to social norms and social limitations.

This recent queer anthropological work offers a productive collaboration between cultural theory, queer theory, and ethnography. But sexuality is a roadblock in this queer anthropological collaboration. I hoped to show that a historical and social constructionist account of sexuality that critiques neoclassical economic subjectivity may help us imagine new pathways for understanding and pursuing research on affection, pleasure, intimacy, and social agency. The category of sexuality orders and limits political economic, anthropological, and queer interpretations of bodies and pleasures and thus human subjectivity. In this sense, I push queer anthropology further by critiquing the continued use of sexuality in this vital research. I maintain that we can build a queer anthropology—without sexuality. 


\section{References}

Adams, Stacy Leigh and Vincanne Pigg

2005 Sex in Development: Science, Sexuality, and Morality in Global Perspective. Durham and London: Duke University Press.

Ahearn, Laura

2001 Invitations to Love: Literacy, Love Letters, and Social Change in Nepal. Ann Arbor: University of Michigan Press.

Allen, Barry

1999 Power/Knowledge. In Critical Essays on Michel Foucault. Karlis Racevskis, ed. Pp. 69-81. New York: G.K. Hall.

Altman, Dennis

2001 Global Sex. Chicago: University of Chicago Press.

Amariglio, Jack and David F. Ruccio

1999 Literary/Cultural "Economies," Economic Discourse, and the Question of Marxism. In The New Economic Criticism: Studies at the Intersection of Literature and Economics. Martha Woodmansee, and Mark Osteen, eds. Pp. 385-394. London: Routledge.

Anderson, Benedict

2006 Imagined Communities: Reflections on the Origin and Spread of Nationalism (New Edition). London and New York: Verso.

Argyrou, Vassos

2002 Anthropology and the Will to Meaning: A Postcolonial Critique. London: Pluto Press.

Bakhtin, M.M. and Michael Holquist

1981 The Dialogic Imagination: Four Essays. Austin: University of Texas Press.

Baumeister, Roy F. and Kathleen D. Vohs

2004 Sexual Economics: Sex as Female Resource for Social Exchange in Heterosexual Interactions. Personality and Social Psychology Review 8:339-363.

Bentham, Jeremy.

1961 The Utilitarians: An Introduction to the Principles of Morals and Legislation. Garden City, N.Y.: Doubleday. 
Bérubé Allan

1990 Coming Out Under Fire: The History of Gay Men and Women in World War Two. New York: Free Press.

Bicchieri , Cristina

1988 Should a Scientist Abstain From Metaphor? In The Consequences of Economic Rhetoric. Arjo Klamer, Deirdre N. McCloskey, and Robert M. Solow, eds. Pp. 104. Cambridge: Cambridge University Press.

Biehl, João Guilherme, Byron Good, and Arthur Kleinman 2007 Introduction: Rethinking Subjectivity. In Subjectivity: Ethnographic Investigations. Pp. 1-24. Berkeley: University of California Press.

Binnie, Jon

2004 The Globalization of Sexuality. London: SAGE.

Biolsi, Tom and Larry Zimmerman

1997 Indians and Anthropologists: Vine Deloria, Jr., and the Critique of Anthropology. Tucson: University of Arizona Press.

Birken, Lawrence

1988 Consuming Desire: Sexual Science and the Emergence of a Culture of Abundance, 1871-1914. Ithaca, N.Y.: Cornell University Press.

Bloch, Iwan, M.D.

1933 Anthropological Studies in the Strange Sexual Practices of all Races in All Ages: Ancient and Modern, Oriental and Occidental, and Primitive and Civilized. New York: Falstaff Press.

1936 The Sexual Life of Our Time: In Its Relations to Modern Civilization. M. Eden Paul, M.D., Trans. London: Rebman Limited.

Boag, Peter Same-Sex Affairs: Constructing and Controlling Homosexuality in

2003 the Pacific Northwest. Berkeley, Los Angeles, and London: University of California Press.

Boellstorff, Tom

2005 The Gay Archipelago: Sexuality and Nation in Indonesia. Princeton and Oxford: Princeton University Press. 
2007a A Coincidence of Desires: Anthropology, Queer Studies, Indonesia. Durham: Duke University Press.

2007b Queer Studies in the House of Anthropology. Annual Review of Anthropology 36:17-35.

Bourdieu, Pierre

1977 Outline of a Theory of Practice. Cambridge, UK: Cambridge University Press.

Bousiou, Pola

2008 The Nomads of Mykonos: Performing Liminalities in a 'Queer' Space. New Directions in Anthropology, Volume 29. Oxford and New York: Berghahn Books.

Bristow, Joseph.

1997 Sexuality. London: Routledge.

Brubaker, Rogers and Frederick Cooper

2000 Beyond "Identity." Theory and Society 29:1-47.

Cameron, Deborah, and Don Kulick

2003 Language and Sexuality. Cambridge: Cambridge University Press.

Carver, Terrell and Véronique Mottier, eds.

1998 Politics of Sexuality: Identity, Gender, Citizenship. London:

Routledge.

Chauncey, George

1994 Gay New York: Gender, Urban Culture, and the Making of the Gay Male World, 1890-1940. New York: Basic Books.

Christie, Jim

2006 California Faces Battle Over Gays in Textbooks. Reuters, April 7.

Chused, Richard H.

1983 Married Women's Property Law 1800-1850. Georgetown Law Journal 71:1359-1366.

Cloud, Dana

2002 Queer Theory and 'Family Values': Capitalism's Utopias of SelfInvention. In Transformation, Marxist Boundary Work in Theory, Economics, Politics, and Culture (2): Marxism, Queer Theory, Gender. Syracuse, NY: The Red Factory. 
Connor, Steven

1997 Postmodernist Culture: An Introduction to Theories of the Contemporary. Oxford: Blackwell.

Crehan, Kate A. F.

2002 Gramsci, Culture, and Anthropology. Berkeley: University of California Press.

Crittenden, Ann

2002 The Price of Motherhood: Why the Most Important Job in the World is Still the Least Valued. New York: Macmillan Holt Books.

Crosby, Christina, Lisa Duggan, and Roderick Ferguson, et al.

2012 Queer Studies, Materialism, and Crisis: A Roundtable Discussion. GLQ: A Journal of Lesbian and Gay Studies 18(1), Jan 1. Durham: Duke University Press.

D'Emilio, John

1997 Capitalism and Gay Identity. In The Gender/Sexuality Reader. Roger N. Lancaster \& Micaela di Leonardo, eds. NY, NY:

Routledge.

Darnell, Regna

2001 Invisible Genealogies: A History of Americanist Anthropology. Lincoln: University of Nebraska Press.

Dean, Carolyn J.

1996 Sexuality and Modern Western Culture. New York: Twayne Publishers.

Decena, Carlos Ulises

2011 Tacit Subjects: Belonging and Same Sex Desire Among Dominican Immigrant Men. Durham: Duke University Press.

Diniz, Simone Grilo, Cecilia De Mello E Souza, and Paula Portella

1998 Not Like Our Mothers. In Negotiating Reproductive Rights:

Women's Perspectives Across Countries and Cultures. Petchesky, Rosalind and Karen Judd, eds. International Reproductive Rights Research Action Group. London and New York: Zed Books, St. Martin's Press.

Doran, Jamie

2010 The Dancing Boys of Afghanistan. DVD. PBS. New York, NY. 
Drucker, Peter

2001 Different Rainbows. Swaffham, UK: GMP Publishers.

Duberman, Martin, Martha Vicinus, and George Chauncey Jr., eds.

1989 Hidden From History: Reclaiming the Gay and Lesbian Past. New York: New American Library.

Duggan, Lisa

2011 Beyond Marriage: Democracy, Equality, and Kinship for a New Century. S\&F Online. Issue 10.1-10.2 Fall 2011/Spring 2012.

Barnard Center for Research on Women. http://sfonline.barnard. edu/a-new-queer-agenda. Last accessed September 8, 2012.

Duncan, Simon and Rosalind Edwards

1997 Lone Mothers and Paid Work-Rational Economic Man or

Gendered Moral Rationalities? Feminist Economics 3(2):29-61.

Eagleton, Terry

2003 After Theory. Cambridge, MA: Basic Books.

Elliott, Michael A.

2002 The Culture Concept: Writing and Difference in the Age of

Realism. Minneapolis: University of Minnesota Press.

Ellis, Havelock

1961 Psychology of Sex [1933]. London, Reading, and Fakenham: Cox and Wyman, Ltd.

Engebretsen, Elisabeth Lund

2008 Queer ethnography in theory and practice: Reflections on Studying Sexual Globalization and Women's Queer Activism in Beijing. Graduate Journal of Social Research 5(2):88-116.

Escoffier, Jeffrey

1998 American Homo: Community and Perversity. Berkeley: University of California Press.

Faderman, Lillian

1991 Odd Girls and Twilight Lovers: A History of Lesbian Life in Twentieth Century America. New York: Columbia University Press.

Folbre, Nancy 
1991 The Unproductive Housewife: Her Evolution in $19^{\text {th }}$ Century Economic Thought. Signs 16(3)(Spring):463-484.

2009 Greed, Lust, Gender: A History of Economic Ideas. Oxford and New York: Oxford University Press.

Foucault, Michel

1978 The History of Sexuality: An Introduction, Volume 1. New York, NY: Vintage Books.

2002 Archaeology of Knowledge [1969]. Trans. A.M. Sheridan Smith. London, New York: Routledge.

Foucault, Michel, Luther H. Martin, Huck Gutman, and Patrick H. Hutton 1988 Technologies of the Self: A Seminar with Michel Foucault. Amherst: University of Massachusetts Press.

Foucault, Michel, and Paul Rabinow, ed.

1994 Ethics: Subjectivity and Truth, Essential Works of Foucault 19541984, Vol. 1. New York: New Press.

Francis, A.M.

2008 The Economics of Sexuality: The Effect of HIV/AIDS on Homosexual Behavior in the United States. Journal of Health Economics 27:675-689.

Freud, Sigmund, and James Strachey 1975 Three Essays on the Theory of Sexuality. New York: Basic Books.

Gallo, Marcia M.

2006 Different Daughters: A History of the Daughters of Bilitis and the Rise of the Lesbian Rights Movement. New York: Carroll and Graf.

Germain, Randall

2000 Globalization in Historical Perspective. In Globalization and Its Critics: Political Economics. New York: St. Martin's Press.

Gopinath, Gayatri

2005 Impossible Desires: Queer Diasporas and South Asian Public Cultures. Durham, NC: Duke University Press.

Gray, John

2000 Two Faces of Liberalism. New York: New Press. 
2007 Straw Dogs: Thoughts on Humans and Other Animals. New York: Farrar, Strauss, and Giroux.

Gray, Mary

2009 Out in the Country: Youth, Media, and Queer Visibility in Rural America. New York and London: New York University Press.

Guzman, Manolo

2006 Gay Hegemony/Latino Homosexualities. New York: Routledge.

Halberstam, Judith

2011 The Queer Art of Failure. Durham and London: Duke University Press.

Halperin, David M.

1990 One Hundred Years of Homosexuality: And Other Essays on Greek Love. New York: Routledge.

Hennessy, Rosemary.

1993 Materialist Feminism and the Politics of Discourse. New York:

Routledge.

1996 Queer Theory, Left Politics. In Marxism Beyond Marxism. Saree Maksdisi, Cesare Casarino, and Rebecca E. Karl, eds. Pp. 214-242. New York: Routledge.

2000 Profit and Pleasure: Sexual Identities in Late Capitalism. New York: Routledge.

2006 Returning to Reproduction Queerly: Sex, Labor, Need. Rethinking Marxism 18(3):405-413.

Herdt, Gilbert

1992 Gay Culture in America: Essays from the Field. Boston: Beacon.

Hirschfeld, Magnus

2001 Homosexuality in Men and Women. Michael A. Lombardi Nash, Trans. Amherst: Prometheus Book.

Hitchcock, Peter

2003 Imaginary States: Studies in Cultural Transnationalism. Urbana: University of Illinois Press.

Hobsbawm, E. J.

1975 The Age of Capital, 1848-1875. New York: Scribner. 
1994 Age of Extremes: The Short Twentieth Century, 1914-1991.

London: Michael Joseph.

Huffer, Lynne

2010 Mad For Foucault: Rethinking the Foundations of Queer Theory. New York: Columbia University Press.

Huggan, Graham

2001 The Postcolonial Exotic: Marketing the Margins. London: Routledge.

Jackson, Charles O.

1996 The Other Americans: Sexual Variance in the National Past. Westport, Conn: Praeger.

Jackson, Margaret

1987 'Facts of Life' or the Eroticization of Women's Oppression?

Sexology and the Social Construction of Heterosexuality. In The Cultural Construction of Sexuality. Pat Caplan, ed. Pp.52-81.

London: Tavistock Publications.

Jagose, Annamarie

1996 Queer Theory: An Introduction. New York: New York University Press.

Jevons, W. Stanley

1957 The Theory of Political Economy, 5th Edition. New York, NY:

Kelley \& Millman, Inc.

1965 The Principles of Economics: A Fragment of a Treatise on the Industrial Mechanism of Society and Other Papers. New York: Augustus M. Kelley.

Johnson, David

2004 The Lavender Scare: The Cold War Persecution of Gays and Lesbians in the Federal Government. Chicago: University of Chicago Press.

Jónasdóttir, Anna G., Valerie Bryson, Kathleen B. Jones, eds.

2011 Sexuality, Gender and Power: Intersectional and Transnational Perspectives. New York and London: Routledge.

Katz, Jonathan Ned. 
1976 Gay American History: Lesbians and Gay Men in the U.S.A. New York: Thomas Crowell.

1997 Heterosexuality and Homosexuality: Questioning the Terms. In A Queer World: The Center for Gay and Lesbian Studies Reader. Martin Duberman, ed. NY: New York University Press.

2001 Love Stories: Sex Between Men Before Homosexuality. Chicago, IL: The University of Chicago Press.

Kimmel, Michael S. and Rebecca F. Plante, eds.

2004 Sexualities: Identities, Behaviors, and Society. New York and Oxford: Oxford University Press.

Kipnis, Laura

2003 Against Love: A Polemic. New York: Pantheon Books.

Klamer, Arjo, Deirdre N. McCloskey, and Robert M. Solow

1988 The Consequences of Economic Rhetoric. Cambridge: Cambridge University Press.

Krafft-Ebing, Richard von

1965 Psychopathia Sexualis: A Medico-Forensic Study. [1894] New York: Bell Publishing Company, Inc..

Kulick, Don and Margaret Willson

1995 Taboo: Sex, Identity and Erotic Subjectivity in Anthropological Fieldwork. London: Routledge.

Kuper, Adam

2003 The Return of the Native. California Forum on Anthropology in Public. Current Anthropology 44(3), June.

Kurasawa, Fuyuki

2004 The Ethnological Imagination: A Cross-cultural Critique of Modernity. Minneapolis: University of Minnesota Press.

Kurtz, Donald V.

2001 Political Anthropology: Power and Paradigms. Boulder, Colo: Westview Press.

Landry, Donna and Gerald MacLean

1993 Materialist Feminisms. Cambridge, Mass: Blackwell.

Lang, Jeremy 
2009 Adams Sex Scandal Leaves Portland's Gay Community Hurt, Divided. The Oregonian, January 24.

Leap, William and Ellen Lewin

1996 Out in the Field: Reflections of Lesbian and Gay Anthropologists. Urbana: University of Illinois Press.

2002 Out in Theory: The Emergence of Lesbian and Gay Anthropology. Urbana: University of Illinois Press.

Lewin, Ellen

1993 Lesbian Mothers. Ithaca: Cornell University Press.

Lindholm, Charles

1998 Love and Structure. Theory, Culture and Society15 (3-4):243-263.

Lyons, Andrew P., and Harriet Lyons

2004 Irregular Connections: A History of Anthropology and Sexuality. Lincoln: University of Nebraska Press.

Lyotard, Jean-François

1984 The Postmodern Condition: A Report on Knowledge. Minneapolis: University of Minnesota Press.

1993 Libidinal Economy. Bloomington: Indiana University Press.

Macdonell, Diana

1986 Theories of Discourse: An Introduction. Oxford: Basil Blackwell.

Manalansan, Martin

2003 Global Divas: Filipino Gay Men in the Diaspora. Durham and London: Duke University Press Books.

Mansfield, Nick

2000 Subjectivity: Theories of the Self from Freud to Haraway. New York: New York University Press.

Marcus, George E., Paul Rabinow, James Faubion, and Tobias Reese

2008 Designs for an Anthropology of the Contemporary. Durham: Duke University Press.

Marcuse, Herbert

1966 Eros and Civilization. Boston: Beacon Press.

Markowitz, Fran and Michael Ashkenazi 
1999 Sex, Sexuality, and the Anthropologist. Urbana: University of Illinois Press.

Marx, Karl and Friedrich Engels

1967 The Communist Manifesto. Baltimore, MD: Penguin Books, Ltd.

1977 The German Ideology: Part One. New York: International Publishers.

1990 Capital. Great Books of the Western World Series. Chicago: Encyclopaedia Britannica, Inc.

McCloskey, Deirdre N.

1998 The Rhetoric of Economics. Madison, Wis: University of Wisconsin Press.

McCloskey, Deidre, Arjo Klamer, and Robert M. Solow

1988 The Consequences of Economic Rhetoric. Cambridge, UK: Cambridge University Press.

McNay, Lois

1994 Foucault: A Critical Introduction. New York: Continuum.

Menger, Carl

1981 Principles of Economics. New York \& London: New York University Press.

Mill, John Stuart

1874 On the Definition of Political Economy and on the Method of Investigation. In Essays on Some Unsettled Questions of Political Economy. Library of Economics and Liberty. Last Retrieved Oct 28, 2012: <http://econlib.org/library/Mill/mlUQP5.html>.

1996 On Liberty and Other Essays. New York: Oxford.

Mills, Sara

1997 Discourse. London: Routledge.

Minitz, Stanley

1982 Sweetness and Power: The Place of Sugar in Modern History. New York: Penguin Books.

Mohanty, Chandra Talpade

1995 Under Western Eyes: Feminist Scholarship and Colonial Discourses. In The Post-Colonial Studies Reader. Bill Ashcroft, 
Gareth Griffiths, and Helen Tiffin, eds. Pp. 242-245. London:

Routledge.

Morton, Donald

1996 The Material Queer: A LesBiGay Cultural Studies Reader.

Boulder, CO: Westview Press.

Nelson, Julie A.

2006 Economics for Humans. Chicago: University of Chicago Press.

Newton, Esther

1979 Mother Camp: Female Impersonators in America. Chicago:

University of Chicago Press.

1993 Cherry Grove, Fire Island: Sixty Years in America's First Gay and Lesbian Town. Boston: Beacon.

Oakley, Allen

1994 Classical Economic Man: Human Agency and Methodology in the Political Economy of Adam Smith and J.S. Mill. Aldershot, Hants, England: E. Elgar.

Oleksy, Elzbieta H., ed.

2009 Intimate Citizenships: Gender, Sexualities, Politics. New York and London: Routledge.

Ortega, Adriana Ortiz, Ana Amuchástegui, and Marta Rivas

1998 Because They Were Born From Me. In Negotiating Reproductive

Rights: Women's Perspectives Across Countries and Cultures.

International Reproductive Rights Research Action Group.

Rosalind Petchesky and Karen Judd, eds. Pp.145-179.London and

New York: Zed Books, St. Martin's Press.

Osteen, Mark and Martha Woodmansee

1999 Taking Account of the New Economic Criticism: An Historical Introduction. In The New Economic Criticism: Studies at the Intersection of Literature and Economics. London, New York: Routledge.

Pack, Spencer J.

1991 Capitalism as a Moral System: Adam Smith's Critique of the Free Market Economy. Aldershot, Hants, England: E. Elgar.

Patterson, Thomas Carl 
2001 A Social History of Anthropology in the United States. Oxford: Berg.

Petchesky, Rosalind and Karen Judd

1998 Negotiating Reproductive Rights: Women's Perspectives Across Countries and Cultures. International Reproductive Rights Research Action Group. London and New York: Zed Books, St. Martin's Press.

Povinelli, Elizabeth A.

2006 The Empire of Love: Toward a Theory of Intimacy, Genealogy, and Carnality. Durham: Duke University Press.

Puar, Jasbir

2007 Terrorist Assemblages: Homonationalism in Queer Times. Durham and London: Duke University Press Books.

Quiroga, Jose

2000 Tropics of Desire: Interventions from Queer Latin America. New York: NYU Press.

Rabinow, Paul

1985 Discourse and Power: On the Limits of Ethnographic Texts.

Dialectical Anthropology, vol. 10, nos. 1-2, Pp. 1-14. Amsterdam.

1994 Introduction: The History of Systems of Thought. In

Ethics: Subjectivity and Truth, Michel Foucault. Pp. xi-xlii. New York: New Press.

2003 Anthropos Today: Reflections on Modern Equipment. Princeton, N.J.: Princeton University Press.

Rajchman, John

1985 Michel Foucault: The Freedom of Philosophy. New York: Columbia University Press.

Regnerus, Mark and Jeremy Uecker

2011 Premarital Sex: How Young People Meet, Mate, and Think About Marrying. Oxford, New York: Oxford University Press.

Reich, Wilhelm

1963 The Sexual Revolution: Toward a Self-Governing Character Structure. New York, NY: Farrar, Straus and Giroux.

Ricardo, David. 
1960 The Principles of Political Economy and Taxation. London: J.M. Dent \& Sons Ltd.

Roseberry, William

2002 Political Economy in the United States. In Culture, economy, Power Anthropology as Critique, Anthropology as Praxis. Winnie Lem and Belinda Leach, eds. Pp. 59-72. Albany: State University of New York Press.

Rothschild, Kurt W.

2001 The Reluctant Rebel or Glamour and Poverty of the Homo Oeconomicus. KYKLOS 54(2/3):445-452.

Rubin, Gayle S.

1984 Thinking Sex: Notes for a Radical Theory of the Politics of Sexuality. In Pleasure and Danger: Exploring Female Sexuality. Carol S. Vance, ed. Pp. 267-293. New York: Routledge and K. Paul.

2002 Studying Sexual Subcultures: Excavating the Ethnographies of Gay Communities in Urban North America. In Out in Theory: The Emergence of Lesbian and Gay Anthropology. Urbana: University of Illinois Press.

2011 Deviations: A Gayle Rubin Reader. Durham: Duke University Press.

Rupp, Leila A Desired Past: A Short History of Same-Sex Love in America.

2002 Chicago: University of Chicago Press.

Said, Edward

1978 Orientalism. New York: Pantheon Books.

Saker, Anne

2009 There's A Sense of Security: Transition Projects' New Shelter Allows Homeless Couples to Sleep Together. The Oregonian, November 6: B1, B8.

Sawicki, Jana

1991 Disciplining Foucault: Feminism, Power, and the Body. New York and London: Routledge.

Scagliotti, John

2005 Dangerous Living: Coming Out in the Developing World. DVD. First Run Features. New York, NY. 
Sedgwick, Eve Kosofsky

1990 Epistemology of the Closet. Berkeley and Los Angeles: University of California Press.

1993 Tendencies. Durham: Duke University Press.

2003 Paranoid Reading and Reparative Reading, Or, You're So

Paranoid, You Probably Think This Essay Is About You. In

Touching Feeling: Affect, Pedagogy, Performativity. Pp. 123-151.

Durham, NC: Duke University Press.

Seidman, Steven

2003 The Social Construction of Sexuality. New York: Norton.

Sinfield, Alan

2004 On Sexuality and Power. New York: Columbia University Press.

Smith, Adam

1909 An Inquiry Into the Nature And Causes Of The Wealth of Nations. The Harvard Classics, Vol. 10. New York: P.F. Collier \& Son Company.

Somerville, Siobhan B.

1994 Scientific Racism and the Emergence of the Homosexual Body. Journal of the History of Sexuality 5(2):243-266.

Spargo, Tamsin

1999 Foucault and Queer Theory. Duxford, Cambridge, UK: Icon Books.

Stocking, George W. (Jr.)

1989 Romantic Motives: Essays on Anthropological Sensibility. Madison, Wis: University of Wisconsin Press.

Stoler, Ann

1995 Race and the Education of Desire: Foucault's History of Sexuality and the Colonial Order of Things. Durham, NC: Duke University Press Books.

2002 Carnal Knowledge and Imperial Power: Race and the Intimate in Colonial Rule. Berkeley: University of California Press.

Strassman, Diana 
1993 Not a Free Market: The Rhetoric of Disciplinary Authority in Economics. Beyond Economic Man: Feminist Theory and Economics. Marianne A. Ferber and Julie A. Nelson, eds. Pp. 5468. Chicago: University of Chicago Press.

Strober, Myra H.

1997 Rethinking Economics Through A Feminist Lens. In Gender and Political Economy: Incorporating Diversity Into Theory and Policy. Armonk, New York: ME Sharpe.

Sullivan, Nikki.

2003 A Critical Introduction to Queer Theory. New York: New York University Press.

Tapley, Heather

2012 Mapping the Hobosexual: A Queer Materialism. Sexualities 15(34):373-390.

Tomer, John F.

2001 Economic Man vs. Heterodox Men: The Concepts of Human Nature in Schools of Economic Thought. The Journal of SocioEconomics 30(2001):281-293.

Tratner, Michael

2002 Deficits and Desires: Economics and Sexuality in Twentieth Century Literature. Palo Alto: Stanford University Press.

Turner, William B.

2000 A Genealogy of Queer Theory. Philadelphia: Temple University Press.

Valentine, David

2007 Imagining Transgender: An Ethnography of a Category. Durham: Duke University Press.

Vance, Carol S.

1989 Social Construction Theory: Problems in the History of Sexuality. In Homosexuality, Which Homosexuality? A. van Kooten Nierkirk and T. Van De Meer, eds. Pp. Amsterdam: An Dekker.

2005 Anthropology Rediscovers Sexuality: A Theoretical Comment. In Same Sex Cultures and Sexualities: An Anthropological Reader. Jennifer Robertson, ed. Malden, Mass: Blackwell Publishing. 
Walras, Léon

1954 Elements of Pure Economics [1877].1954 Edition. New York: Augustus M. Kelley.

Warner, Michael

1999 The Trouble With Normal: Sex, Politics, and the Ethics of Queer Life. Cambridge: Harvard University Press.

Weeks, Jeffrey

1991 Against Nature: Essays on History, Sexuality, and Identity. London: Rivers Oram Press.

1995 Invented Moralities: Sexual Values in an Age of Uncertainty. New York: Columbia University Press.

Weston, Kath

1991 Families We Choose: Lesbians, Gays, Kinship. New York:

Columbia University Press.

1993 Lesbian/Gay Studies in the House of Anthropology. Annual Review of Anthropology 22:339-367.

1998 Long, Slow Burn: Sexuality and Social Science. New York: Routledge.

Wilchins, Riki

2004 Queer Theory, Gender Theory: An Instant Primer. Los Angeles, CA: Alyson Publications.

Williams, Mary E., ed.

2006 Sex: Opposing Viewpoints. Opposing Viewpoints Series, Helen Cothran, ed. Farmington Hill, MI: Greenhaven Press.

Williams, Raymond

1976 Keywords: A Vocabulary of Culture and Society. New York:

Oxford University Press.

Wittig, Monique

1978 The Straight Mind. Feminist Issues 1(1):103-111. New York: MLA.

Wolf, Eric R.

1982 Europe and the People Without History. Berkeley: University of California Press. 
Wolf, Sherry

2009 Sexuality and Socialism: History, Politics, and Theory of LGBT Liberation. Chicago: Haymarket Books.

Wuthnow, Robert, James Davidson Hunter, Albert Bergesen and Edith Kurzweil 1984 Cultural Analysis: The Work of Peter L. Berger, Mary Douglas, Michele Foucault, and Jurgen Habermas. Boston, London:

Routledge \& Kegan Paul. 